\title{
Visual Recognition in Monkeys Following Rhinal Cortical Ablations Combined with Either Amygdalectomy or Hippocampectomy
}

\author{
E. A. Murray and M. Mishkin \\ National Institute of Mental Health, Laboratory of Neuropsychology, Bethesda, Maryland 20892
}

Performance on a visual recognition task was assessed in cynomolgus monkeys with ablations of rhinal (i.e., ento-, pro-, and perirhinal) cortex in combination with either amygdalectomy or hippocampectomy, as well as in unoperated controls. Removal of the hippocampal formation plus rhinal cortex resulted in a mild recognition deficit, whereas removal of the amygdaloid complex plus rhinal cortex resulted in a severe deficit. Comparison of the results with those of an earlier study (Mishkin, 1978) indicates that adding a rhinal cortical removal to hippocampectomy yields little, if any, additional impairment in recognition. By contrast, adding a rhinal cortical removal to an amygdalectomy has a profound effect; indeed, the recognition impairment in monkeys with amygdaloid plus rhinal removals was at least as severe as that seen in monkeys with combined amygdaloid and hippocampal removals. Taken together, these results support the conclusion that combined damage to the amygdaloid and hippocampal systems is necessary to produce a severe recognition deficit. In addition, they suggest that the effect of ablating the rhinal cortex is equivalent to that of removing the entire hippocampal formation, presumably because the rhinal cortical ablation disconnects the hippocampus from its neocortical input.

In macaques, a severe recognition deficit in both vision and touch follows combined but not separate ablation of the amygdaloid complex and hippocampal formation (Mishkin, 1978; Murray and Mishkin, 1984; Saunders et al., 1984). These 2 structures are rarely removed without concomitant damage to other temporal lobe structures, however, and this has raised the possibility that the associated damage is actually responsible for the deficit. For most of the alternative loci of injury, this possibility has by now been ruled out. For example, inadvertent damage to the tail of the caudate nucleus and the inferior temporal cortex has been eliminated as the cause, since there are now histologically verified instances of severely impaired animals without any such damage (Murray and Mishkin, 1984; Zola-Morgan and Squire, 1985). Furthermore, deliberate lesions of some of the structures in question have been shown to be insufficient. Thus, bilateral transection of the white matter of the temporal stem has failed to yield a recognition deficit (ZolaMorgan et al., 1982) and ablation of the inferior temporal cortex yields a memory deficit in vision only (Moss et al., 1981), not the bimodal deficit that follows limbic ablations (Moss et al., 1981; Murray and Mishkin, 1984).

\footnotetext{
Received Oct. 7, 1985; revised Dec. 3, 1985; accepted Jan. 13, 1986.

A preliminary report of this work has appeared elsewhere (Murray and Mishkin, 1983). We thank David Kramer, Louis Cali, Mimi Brickson, Terri Pavelko, and Kurt Brattain for their help with testing the monkeys, Leon Dorsey and Linton Stokes for their valuable technical assistance, and Karen Pettigrew for her help with the statistical analyses.

Correspondence should be addressed to Elizabeth A. Murray, Laboratory of Neuropsychology, National Institute of Mental Health, Building 9, Room IN107, Bethesda, MD 20892.

Copyright (C) 1986 Society for Neuroscience $0270-6474 / 86 / 071991-13 \$ 02.00 / 0$
}

One alternative, however, has not been eliminated. As shown in Figure 1, the amygdala directly overlies the anterior half of the entorhinal cortcx, and the hippocampal formation directly overlies the posterior half. Any attempt to spare this cortical tissue necessarily increases the likelihood of amygdaloid or hippocampal sparing, and, consequently, in the studies in which the effects of separate and combined amygdaloid and hippocampal lesions were compared, the anterior entorhinal cortex was routinely removed in the amygdalectomy, and the posterior entorhinal cortex was routinely removed in the hippocampectomy. As a result, the entire extent of entorhinal cortex was removed when, and only when, both the amygdala and the hippocampus were ablated in combination. This analysis raises the possibility that the entorhinal cortical damage could have contributed substantially to the impairment.

The entorhinal cortex projects not only through the perforant pathway to the hippocampal formation but also, through an independent pathway, to a second structure that has been implicated in memory, namely, the medial dorsal nucleus of the thalamus (Aggleton and Mishkin, 1983, 1984; Victor et al., 1971). The entorhinal cortex could thus be making a contribution to memory independent of that made by the hippocampal formation itself and, consequently, the memory deficit previously interpreted as an effect of combined hippocampal and amygdaloid damage might have been due instead to combined hippocampal and entorhinal damage.

There is still another way, however, in which the complete removal of entorhinal cortex could have contributed to the impairment. Even if combined damage to both the amygdaloid and hippocampal systems is in fact necessary for the induction of a severe recognition deficit, the monkeys with the combined lesion could have been impaired independently of the hippocampectomy, since the entorhinal cortical removal might have deafferented the hippocampal formation from its neocortical inputs and thereby rendered the hippocampal formation nonfunctional.

In short, entorhinal cortical damage could have contributed to the earlier findings in either of 2 different ways, i.e., by deafferenting the medial dorsal nucleus of the thalamus, in which case the amygdalectomy may have been superfluous, or by deafferenting the hippocampal formation, in which case the hippocampectomy may have been superfluous. The present experiment was undertaken to determine whether either of these possibilities could have accounted for the earlier results (Mishkin, 1978; Murray and Mishkin, 1984; Saunders et al., 1984).

\section{Materials and Methods}

\section{Experimental plan}

The periallocortex within and adjacent to the rhinal sulcus is comprised of 3 major cytoarchitectonic ficlds (Van Hoesen and Pandya, 1975a): (1) the entorhinal cortex, which lies on the ventral surface of the brain, medial to the rhinal sulcus; (2) the prorhinal cortex, which occupies the medial bank of the rhinal sulcus; and (3) the perirhinal cortex, which 

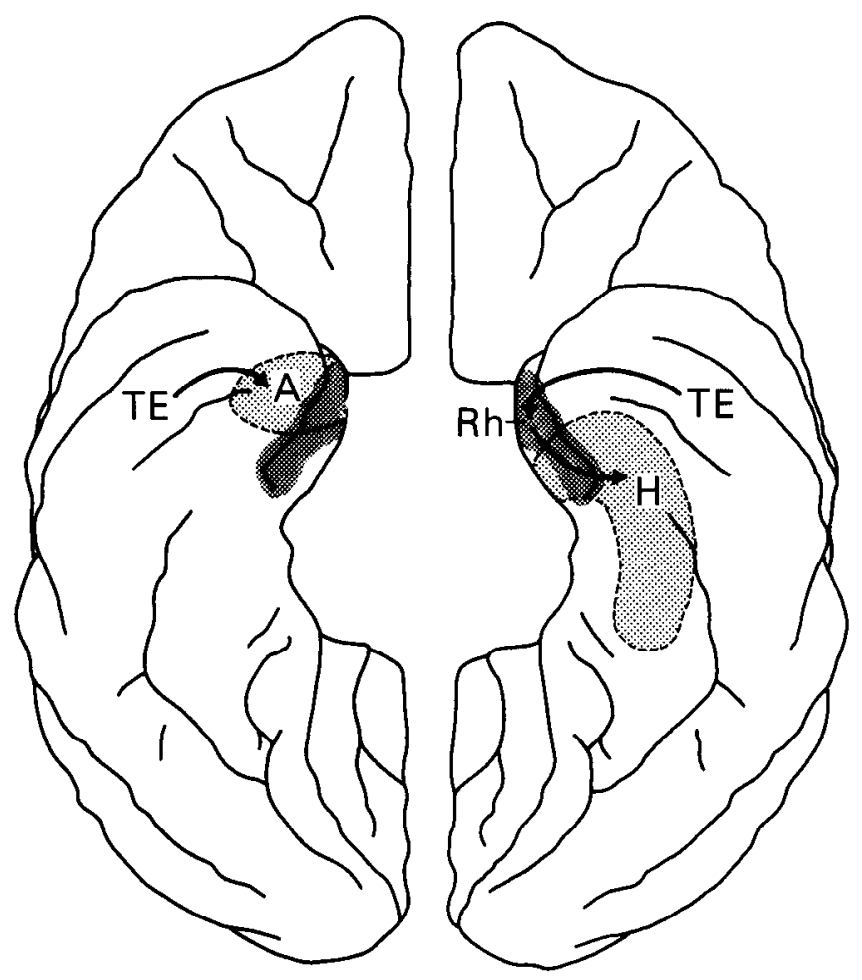

Figure 1. Schematic diagram of the ventral view of the monkey brain. Locations of amygdala $(A)$ and hippocampus $(H)$ in the medial temporal lobe are shown on left and right sides of figure, respectively. Rhinal $(R h$; i.e., ento-, pro-, and perirhinal) cortex is shown in dark shading. Arrows, Flow of visual information from inferior temporal cortex, area TE (Bonin and Bailey, 1947), to amygdala directly and to hippocampus indirectly through entorhinal cortex. Note that the amygdala overlies the anterior half of the rhinal cortex, which is routinely removed in an aspiration lesion of the amygdala, and the hippocampal formation overlies the posterior half of the entorhinal cortex, which is likewise routinely removed in an aspiration lesion of the hippocampus. As a consequence, the entire rhinal cortex is ordinarily removed in a combined amygdaloid and hippocampal ablation.

occupies the lateral bank of the rhinal sulcus. The ento- and prorhinal fields together give rise to the perforant pathway, which terminates on granule cells of the dentate gyrus as well as on distinct dendritic zones of the pyramidal cells of the hippocampus (Van Hoesen and Pandya, 1975a); the perirhinal field projects to the ento- and prorhinal fields (Van Hoesen and Pandya, 1975a); and all 3 of the periallocortical fields project, via the ventral amygdalofugal pathway and inferior thalamic peduncle, to the medial dorsal nucleus of the thalamus (Aggleton and Mishkin, 1984; Aggleton et al., 1986). Since all 3 of these cytoarchitectonic fields might thus be contributing to memory processes by relaying sensory inputs into either the hippocampal formation, the medial dorsal nucleus of the thalamus, or both, we have removed all 3 fields together in the present experiment, referring to them as "rhinal cortex" (Rh). The location of this cortex on the ventral surface of the temporal lobe is shown schematically in Figure 1.

To determine if ablation of either the hippocampal formation plus rhinal cortex $(\mathbf{H}+\mathbf{R h})$ or the amygdaloid complex plus rhinal cortex $(\mathrm{A}+\mathrm{Rh})$ was sufficient to produce a severe memory deficit, we tested monkeys with such lesions on the trial-unique version of delayed nonmatching-to-sample (DNMS). We also tested the animals on pattern discrimination learning and delayed response to determine whether any impairment produced by the lesions would be selective for recognition memory.

\section{Subjects}

The subjects were 13 naive cynomolgus monkeys (Macaca fascicularis) ranging in weight from 3.2 to $4.5 \mathrm{~kg}$ at the beginning of the study. (Although an important comparison group was comprised of rhesus monkeys, monkeys of that species were unavailable at the time the present study was initiated.) Preoperatively, all monkeys were trained on DNMS by methods detailed below. Six monkeys then received bilateral ablations of the hippocampal formation plus rhinal cortex $(\mathrm{H}+$ $\mathrm{Rh}) ; 3$ received bilateral ablations of the amygdaloid complex plus rhinal cortex $(A+R h)$; and 4 remained as unoperated controls. Two of the monkeys with the $\mathrm{H}+\mathrm{Rh}$ ablations and all 4 of the controls were unavailable for testing on either the visual pattern discriminations or spatial delayed response. For these tasks, therefore, the scores of 3 unoperated cynomolgus monkeys from an earlier study (Aggleton and Mishkin, 1983), with training histories that were almost identical to those of the monkeys in the present study, served as the basis for comparison. All monkeys were maintained on a diet of monkey chow supplemented with fruit and vitamins plus iron. Water was always available.

\section{Surgery}

All surgery was performed aseptically in one stage while the animals were under ketamine hydrochloride $(10 \mathrm{mg} / \mathrm{kg})$ and Nembutal $(20-30$ $\mathrm{mg} / \mathrm{kg}$ ) anesthesia. Heart rate, respiration rate, and temperature were monitored throughout the procedure. The ablations were made by aspiration of tissue under visual control with the aid of an operating microscope. Following surgery, the wounds were closed in anatomical layers. Dexamethasone phosphate $(0.4 \mathrm{mg} / \mathrm{kg})$ was administered for 1 $\mathrm{d}$ preoperatively, and both dexamethasone phosphate and gentamicin sulfate $(5.0 \mathrm{mg} / \mathrm{kg})$ were administered for 1 week postoperatively to reduce swelling and to prevent infection, respectively.

The $\mathrm{H}+\mathrm{Rh}$ removal was made via a subtemporal approach through a supralabyrinthine cranial opening. Tissue just medial to the anterior end of the occipitotemporal sulcus was entered with a small-gauge sucker until the ventricle was opened. The hippocampal formation was then retracted from the roof of the ventricle, followed anteriorly and posteriorly, and aspirated. Following removal of the hippocampus plus parahippocampal gyrus, the part of the rhinal sulcus ventral to the amygdala was visualized, and the ablation was extended anteriorly to include both banks of the sulcus and the tissue medial to the sulcus on the ventral surface. The anterior boundary of the ablation was the point at which the rhinal sulcus turned sharply dorsally toward the lateral fissure. The remaining boundaries of the ablation were the occipitotemporal sulcus ventrolaterally, the roof of the ventricle dorsally, and the brain stem medially.

The $\mathrm{A}+\mathrm{Rh}$ removal was made through a subfrontal approach via a supraorbital cranial opening. Tissue medial to the anterior tip of the rhinal sulcus was entered with the sucker. The amygdala was removed by aspiration and then the ablation was extended ventrocaudally to include the subhippocampal tissue lining both banks of the rhinal sulcus as well as the tissue medial to the sulcus on the ventral surface. The boundaries of the ablation consisted of the white matter of the temporal stem laterally, the lip of the lateral bank of the rhinal sulcus ventrolaterally, the pes hippocampus dorsocaudally, and the end of the rhinal sulcus ventrocaudally.

\section{Histology}

At the conclusion of behavioral testing the monkeys were given a lethal dose of Nembutal and perfused intracardially with saline followed by $10 \%$ formalin. The brains were then removed, embedded in celloidin, and sectioned in the coronal plane at $25 \mu \mathrm{m}$, and every 10th section was stained with thionin. Coronal sections through the lesions and surface views for 5 of the 6 cases with $H+R h$ ablations are illustrated in Figures 2-5, and those for the 3 cases with $\mathrm{A}+\mathrm{Rh}$ ablations are shown in Figures 6-8.

The surface area of the rhinal cortex of each hemisphere was calculated for 4 cynomolgus monkeys that were in the same weight range as the monkeys in the present study. These animals had received lesions outside of the temporal lobe, and their brains had been prepared in the same manner as those of the monkeys in the present study. First, ento-, pro-, and perirhinal cortical areas were identified according to the cytoarchitectonic criteria of Van Hoesen and Pandya (1975a), and their borders delineated on projection drawings of coronal sections taken at $0.5 \mathrm{~mm}$ intervals. A map reader was then used to measure the linear distance of each rhinal area both along the pial surface and, separately, along the white matter-cortical boundary on each section in which the area appeared. The mean linear distance of the rhinal subdivisions, defined as the average of the 2 linear measures across all the measured sections, was then corrected for magnification factor and multiplied by the anterior-posterior (A-P) distance between first and last sections for a measure of surface area. This measure was then corrected for shrinkage 


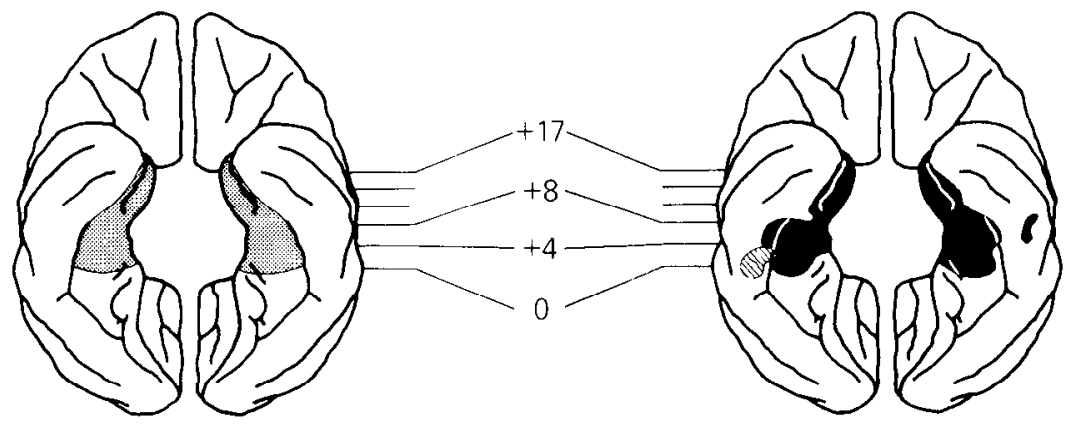

$\mathrm{H}+\mathrm{Rh}$ Intended
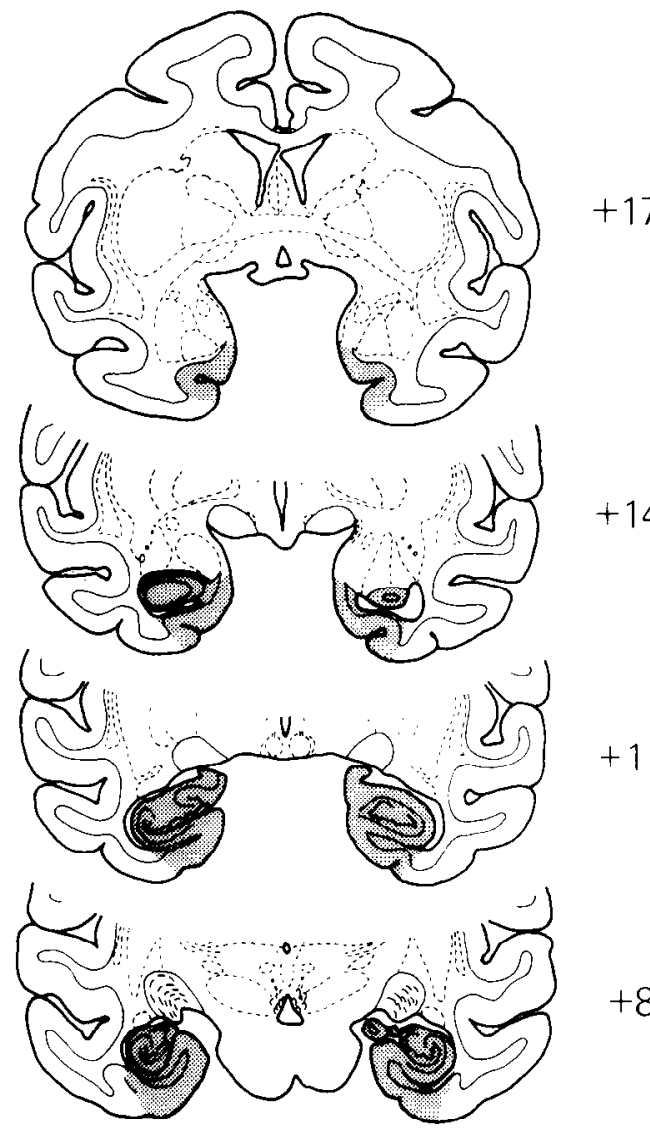

$+11$

$+14$

$\mathrm{H}+\mathrm{Rh}$ Case 6

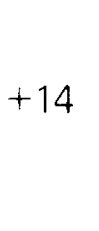

$+8$
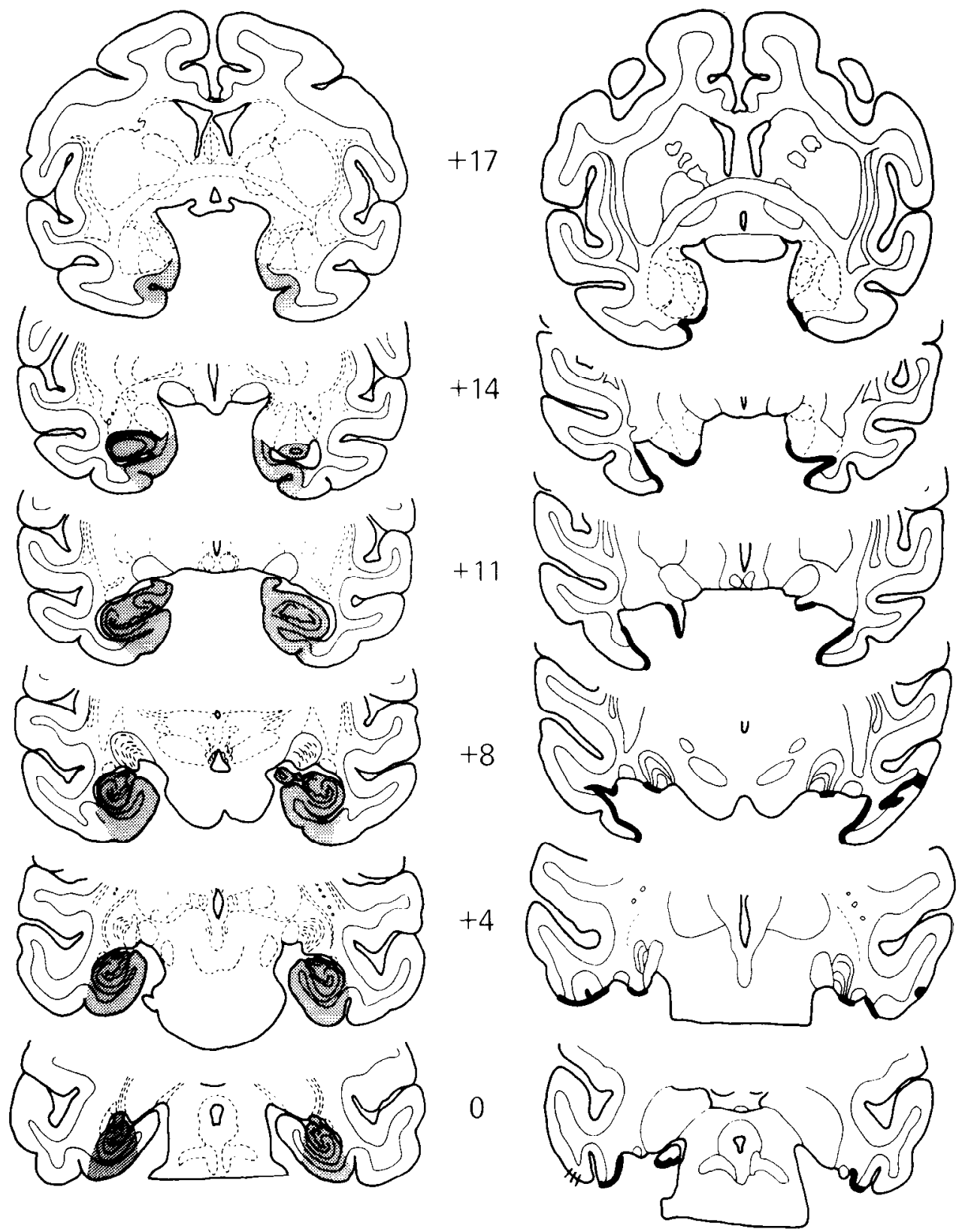

Figure 2. Ablation of hippocampal formation $(H)$ plus rhinal cortex $(R h)$, intended and case 6. Shaded regions, left column, Intended lesion on ventral surface view of brain (top) and on coronal sections (below). Numerals, Approximate distance (in $\mathrm{mm}$ ) from the interaural plane. Column on right, Surface reconstruction and coronal sections of actual lesion in case 6. On the ventral view (top), black indicates complete damage and oblique hatching superficial damage. On the coronal sections (below), the border of the lesion is marked by heavy black lines, and hatchmarks indicate the superfcial damage. Note bilateral infarction in white matter at section +8 , which extended a few millimeters more posteriorly on either side, presumably undercutting inferior temporal cortex. For ease in visual matching to coronal sections, the surface views are shown with hemispheres reversed (i.e., left hemisphere is on the left). resulting from the celloidin-embedding procedure. The amount of rhinal tissue spared in each of the operated monkeys was calculated in the same manner.

Since the ento- and prorhinal fields together give rise to the perforant pathway, the surface areas of these 2 fields were combined into a single value. The control monkeys had an average of $33 \mathrm{~mm}^{2}$ of ento- and prorhinal cortex and $14 \mathrm{~mm}^{2}$ of perirhinal cortex per hemisphere, for a total of $47 \mathrm{~mm}^{2}$ of rhinal tissue per side. Since all cortical sparing in the operated monkeys was roughly symmetrical bilaterally, the values for the 2 sides were averaged. This average value of spared tissue, expressed both in absolute terms and in terms of percentage of normal, is given for each monkey in Table 1. Of the 6 monkeys with $\mathrm{H}+\mathrm{Rh}$ 


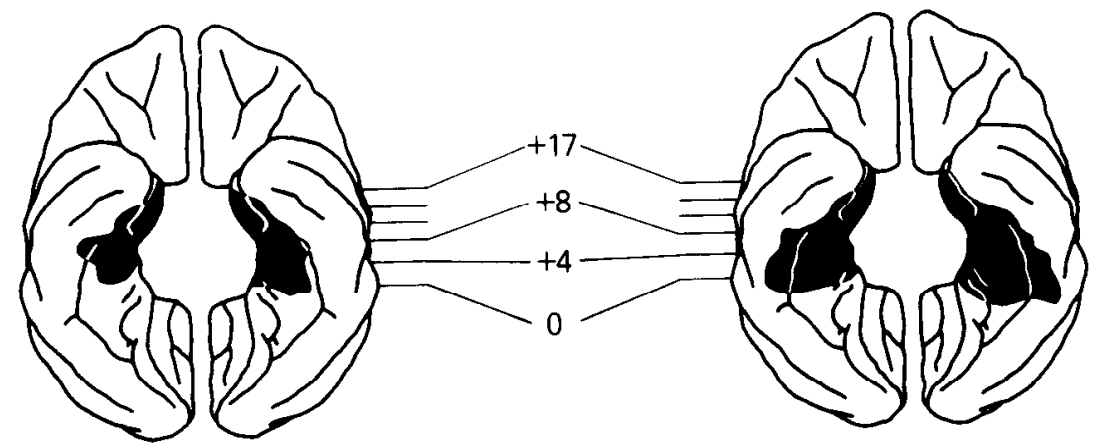

$\mathrm{H}+\mathrm{Rh}$ Case 1
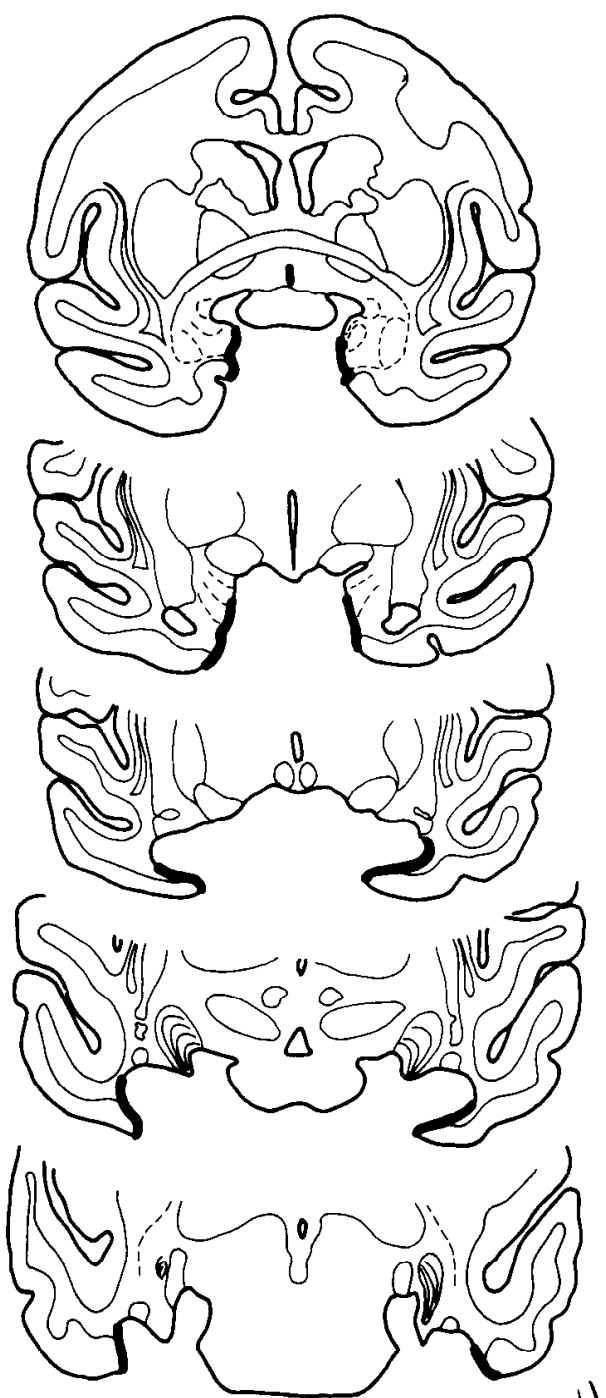

Figure 3. Ablations of hippocampal formation $(H)$ plus rhinal cortex $(R h)$, cases 1 and 2 . Note slight sparing of left hippocampus (at level 0 ) in case 1 , and unintended damage to posterior inferior temporal cortex (at levels +4 and 0 ) in case 2 . Conventions as in Figure 2.

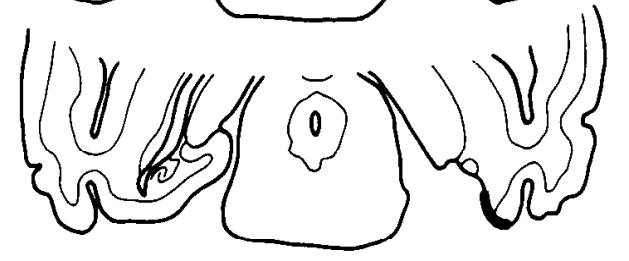

$\mathrm{H}+\mathrm{Rh}$ Case 2

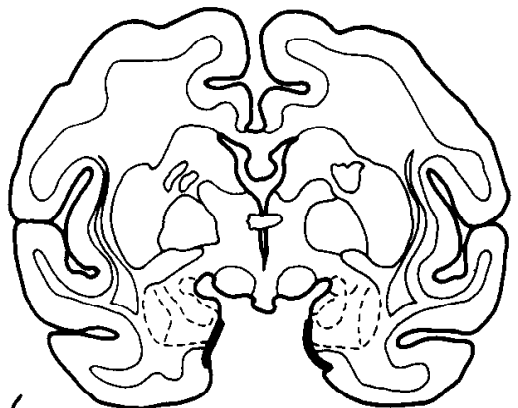

$+14$
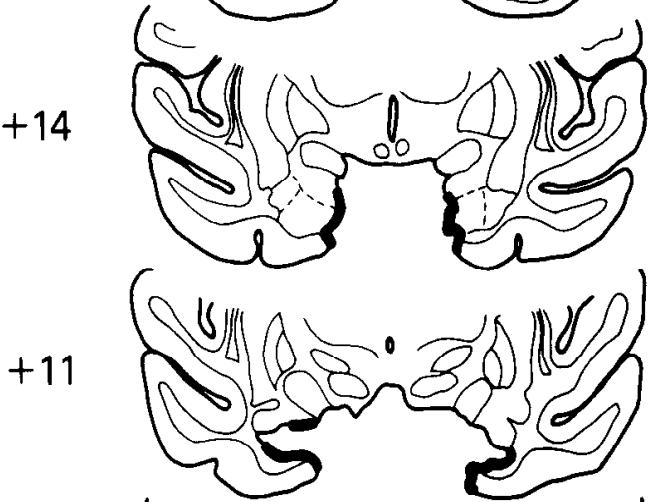

$+8$

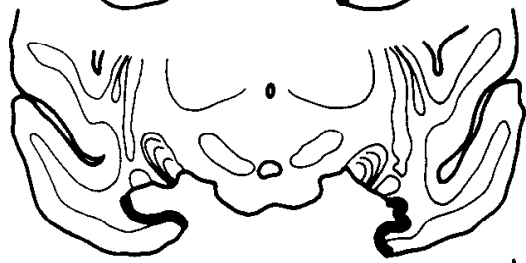

$+4$
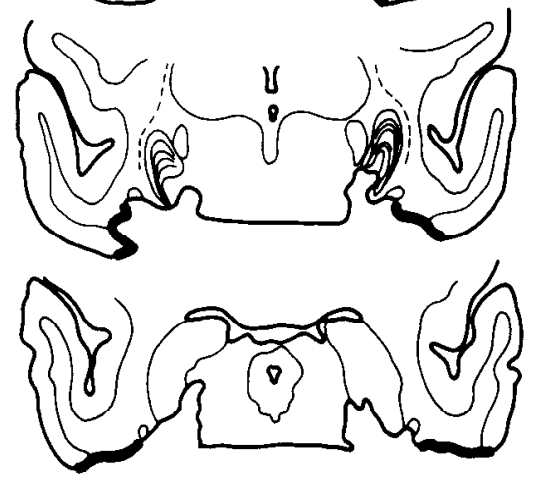

removals, 2 , cases 5 and 6 , had complete lesions of ento- and prorhinal cortex and nearly complete perirhinal lesions; the small amount of spared perirhinal cortex, located rostral to the anterior limit of entorhinal cortex (Van Hoesen and Pandya, 1975a), comprised approximately $4 \%$ of the total extent of rhinal cortex. In the remaining monkeys of the group, there was somewhat greater sparing than this anteriorly. In cases $1-3$, the amount ranged from about 11 to $22 \%$, nearly all of which was located under the anterior half of the amygdala, whereas in case 4 the amount was $45 \%$. Cases 1 and 3 had sparing, in addition, of the posterior $2 \mathrm{~mm}$ of the left hippocampal formation. In cases $2,4,5$, and 6 , there was 


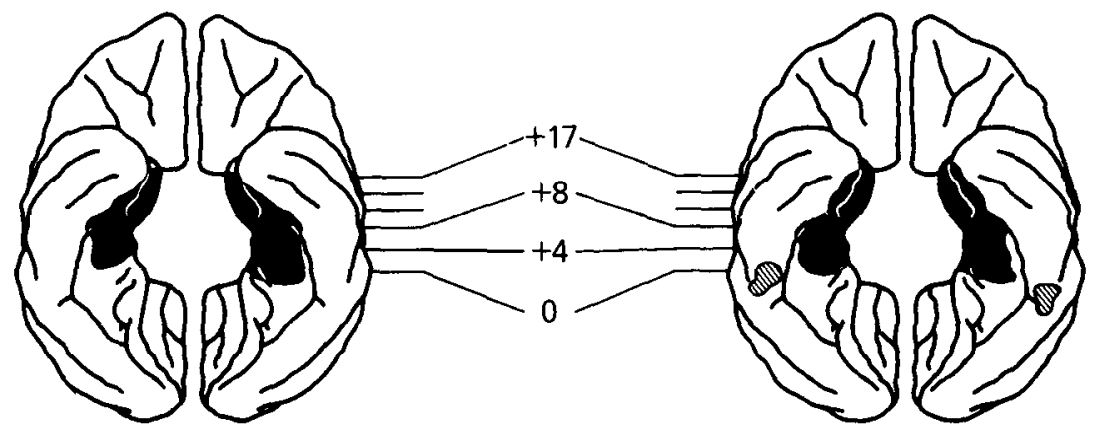

$\mathrm{H}+\mathrm{Rh}$ Case 3
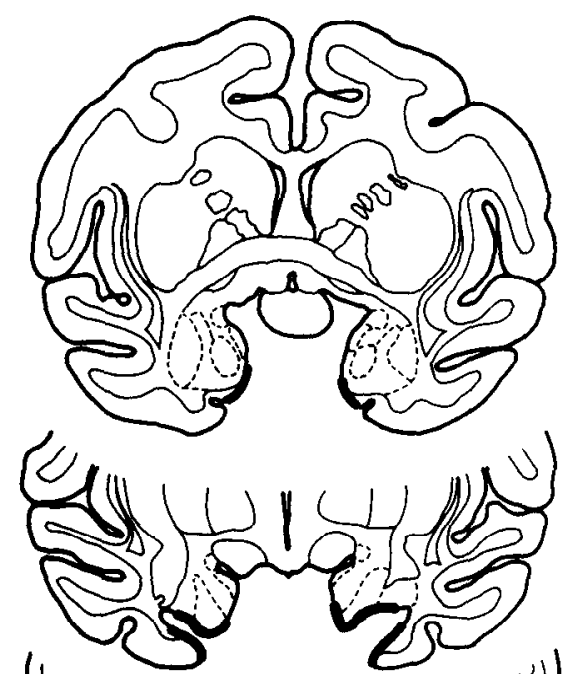

L
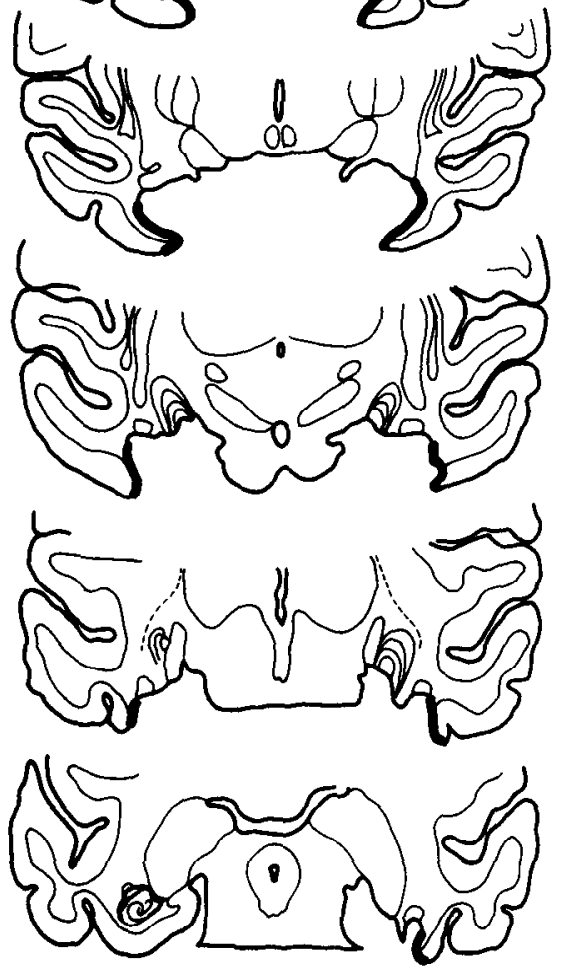

$\mathrm{H}+\mathrm{Rh}$ Case 5

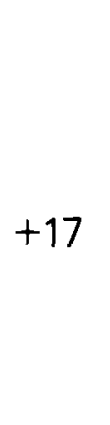

$+14$

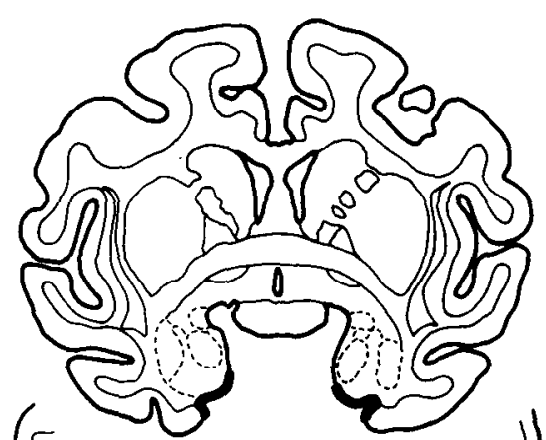

$(\mathrm{C}$

)

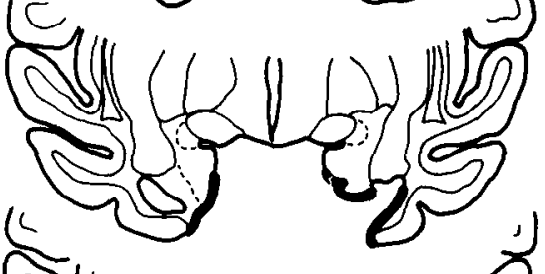

$+11$

$+8$

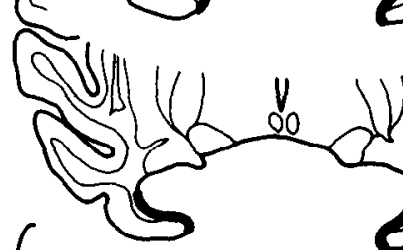

$+4$
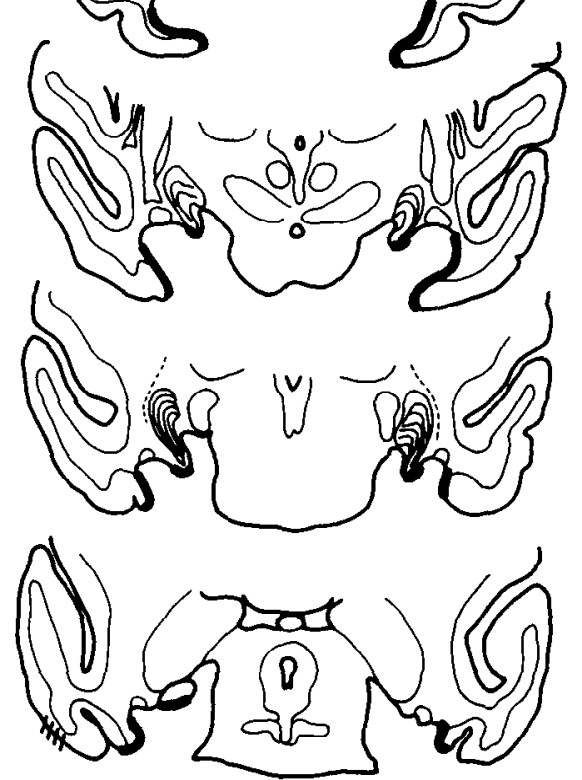

Figure 4. Ablations of hippocampal formation $(H)$ plus rhinal cortex $(R h)$, cases 3 and 5 . Note slight sparing of entorhinal and perirhinal cortex bilaterally (at level +17 ) in case 3 . Conventions as in Figure 2. inadvertent damage bilaterally to the posterior inferior temporal cortex in the region that was raised in order to gain access to the hippocampus. Case 6 had the most extensive damage, caused by infarctions involving the white matter bilaterally (see Fig. 2 , right column, section +8 ). In addition, case 4 sustained a small infarct to the right anterior inferior temporal cortex.
The amygdaloid complex and both banks of the rhinal sulcus were completely removed from all 3 monkeys given the $\mathrm{A}+\mathrm{Rh}$ ablations. The only rhinal tissue spared, amounting to $15-19 \%$, was located slightly beyond the caudal end of the rhinal sulcus in cases 1 and 2 . Case 1 sustained a small amount of damage to the anterior end of the pes hippocampus that extended about $2 \mathrm{~mm}$. Other unintended damage 


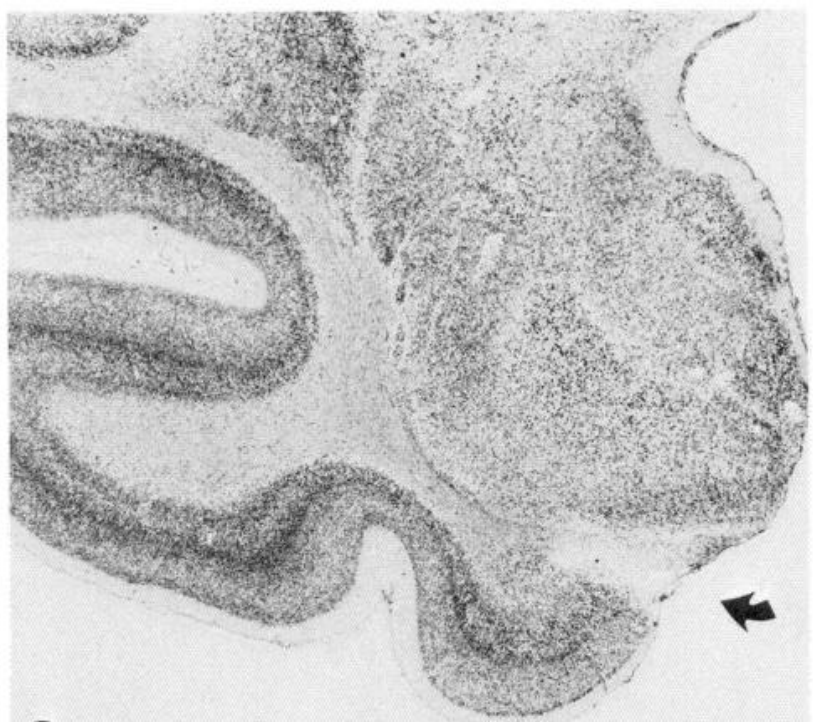

a

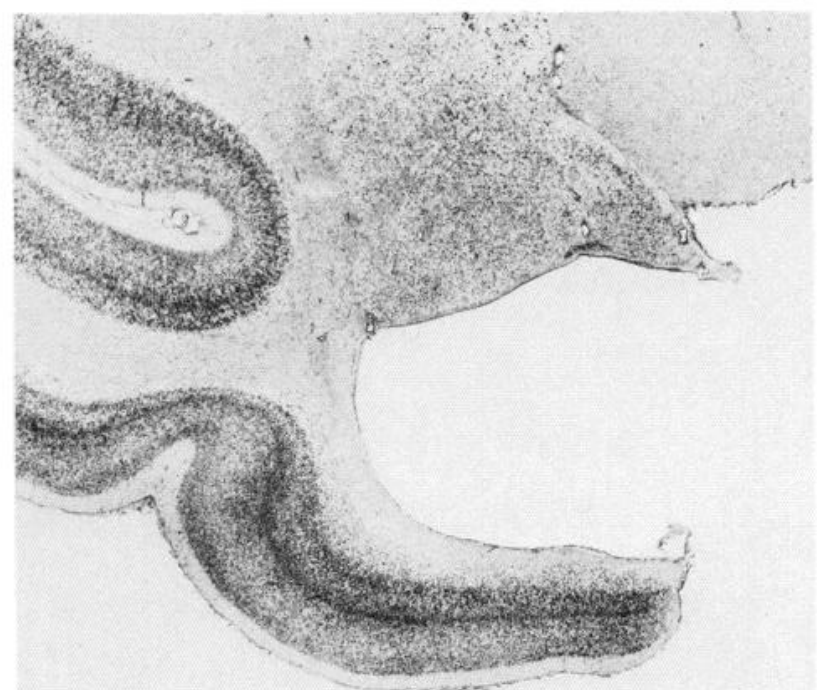

C
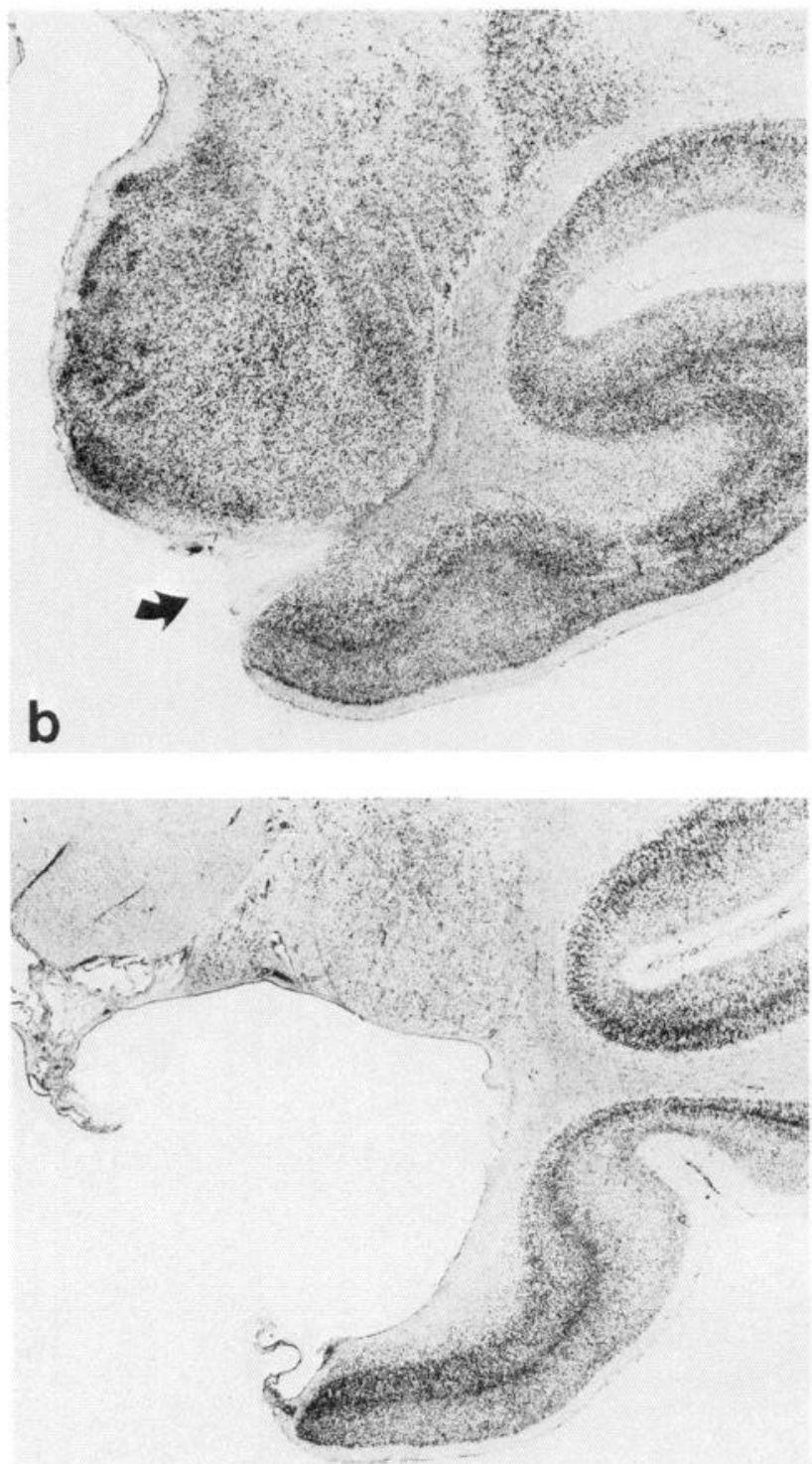

d

Figure 5. Photomicrographs of Nissl-stained coronal sections through the lesion in $\mathrm{H}+\mathrm{Rh}$ case 5 . Views of the left side $(a)$ and right side $(b)$ of a single section at the level of the anterior commissure (at approximately +17$)$, and of the left side $(c)$ and right side $(d)$ at the level of the anterior tip of the hippocampus (at approximately +12 ). Note the removal of the banks of the rhinal sulcus (arrows in $a$ and $b$ ), as well as removal of hippocampal formation and underlying rhinal cortex at the more posterior levels $(c$ and $d)$. Compare with Figure 8.

was limited to the tail of the caudate nucleus: Case 2 had unilateral damage that extended back from the rostral tip about $3 \mathrm{~mm}$ on the left (see Fig. 7, left column), whereas cases 1 and 3 had more extensive bilateral damage that extended about 2 and $4 \mathrm{~mm}$, respectively, on the left, and $8 \mathrm{~mm}$ in each on the right (see Figs. 6 and 7, right columns).

\section{Training procedures}

\section{Delayed nonmatching-to-sample}

Testing was conducted in a Wisconsin General Testing Apparatus (WGTA) in a room lined with sound-attenuating tiles. Additional soundmasking was provided by a generator that produced approximately 60 $\mathrm{dB}$ of white noise. The test tray contained a row of 3 food wells spaced $15 \mathrm{~cm}$ apart, center to center. All monkeys were trained preoperatively on visual DNMS with trial-unique objects (Mishkin and Delacour, 1975). In brief, the monkeys displaced a sample object overlying the central well of the test tray for a banana pellet ( $300 \mathrm{mg}$; P. J. Noyes Co.), and then, $10 \mathrm{sec}$ later, obtained a second pellet if they avoided the sample and displaced instead a novel object, the 2 objects now overlying the lateral wells of the test tray. The left-right position of the novel object on the choice test followed a predetermined, pseudorandom schedule. Daily test sessions consisted of 20 trials separated by $30 \mathrm{sec}$ intervals. The pool from which the stimuli were drawn consisted of approximately 1300 three-dimensional objects differing widely in color, shape, size, and texture. The objects were stored in groups of 20 in numbered plastic bags, and the bags were used in sequence so that a given object did not reappear more often than approximately once every 6 weeks. On attaining the criterion of 90 correct responses in 100 trials, the animals either received the surgery described above or were left as unoperated controls.

After a 2 week rest period, the monkeys were retrained on DNMS to the same criterion as before or for a maximum of 2000 trials. All monkeys were then given a performance test, adapted from Gaffan 


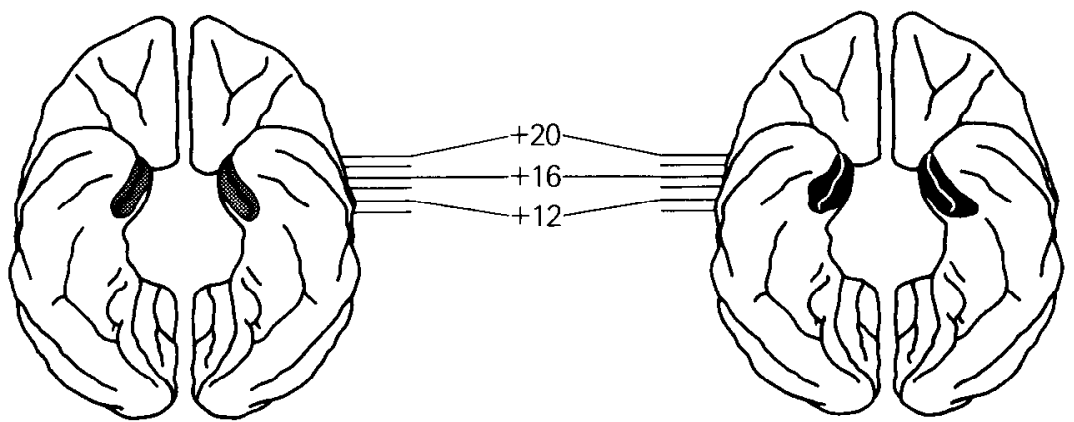

A + Rh Intended $A+R h$ Case 1

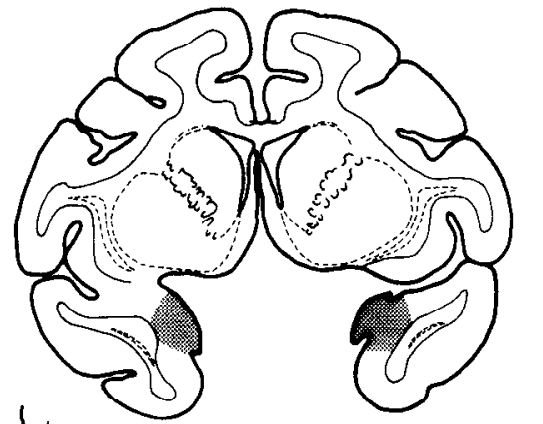

$+20$

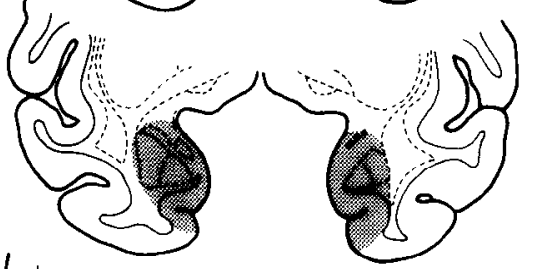

$+18$
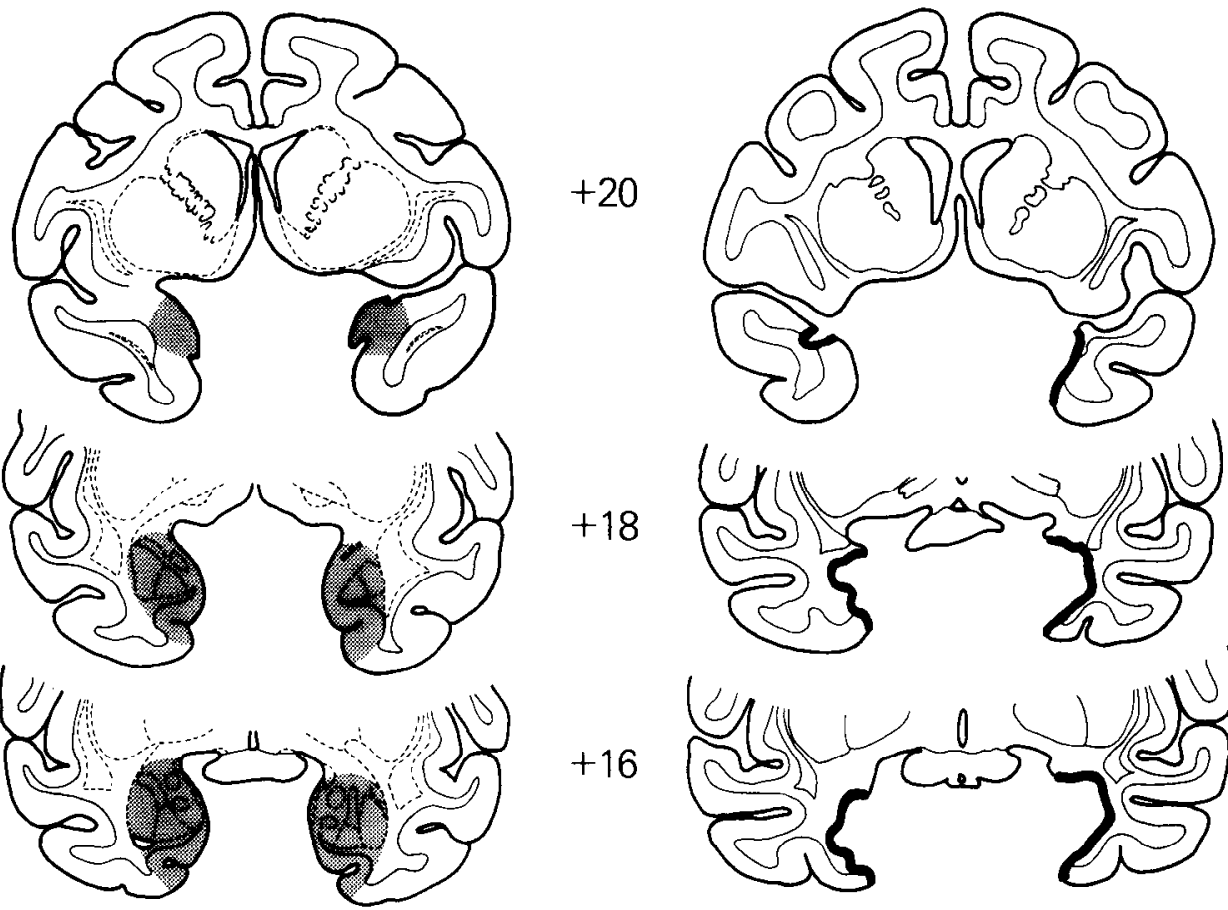

$+16$
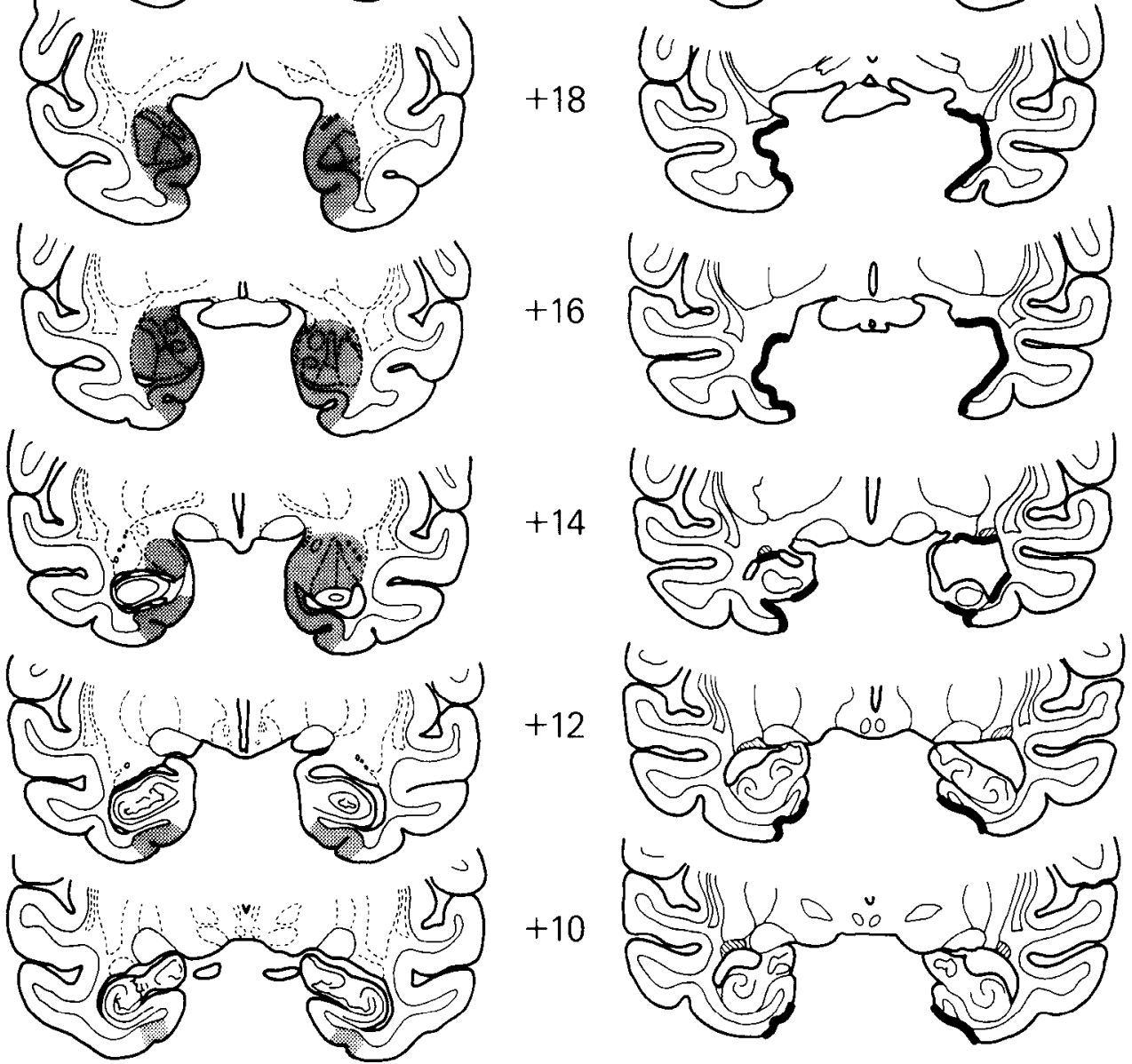

Figure 6. Ablation of amygdaloid complex $(A)$ plus rhinal cortex $(R h)$, intended and case 1 . Shaded regions in left column, Intended lesion on ventral surface view of brain (top) and on coronal sections (below). Column on right, Actual lesion in case 1 reconstructed onto surface view of brain (top) and coronal sections through the lesion (below). Note damage to the tail of the caudate nucleus bilaterally (at levels $+14,+12$, and +10 ), indicated by oblique hatching. Conventions as in Figure 2.
(1974), in which (1) delays of 30,60 , and 120 sec were interposed between the sample presentation and choice test for blocks of 100 trials each, and (2) lists of 3,5 , or 10 sample objects were presented successively prior to the choice tests for blocks of 150 trials each, with $20 \mathrm{sec}$ intervals separating all stimulus presentations. Monkeys were tested for 20 and 30 trials/d on the delay and list-length conditions, respectively.

\section{Visual pattern discriminations}

Following completion of postoperative DNMS testing, 4 of the 6 monkeys with $H+R h$ removals (cases 1 and 4-6) and the 3 with $A+R h$ removals were trained on 2 visual pattern discrimination problems in a manner identical to that described elsewhere (Aggleton and Mishkin, 


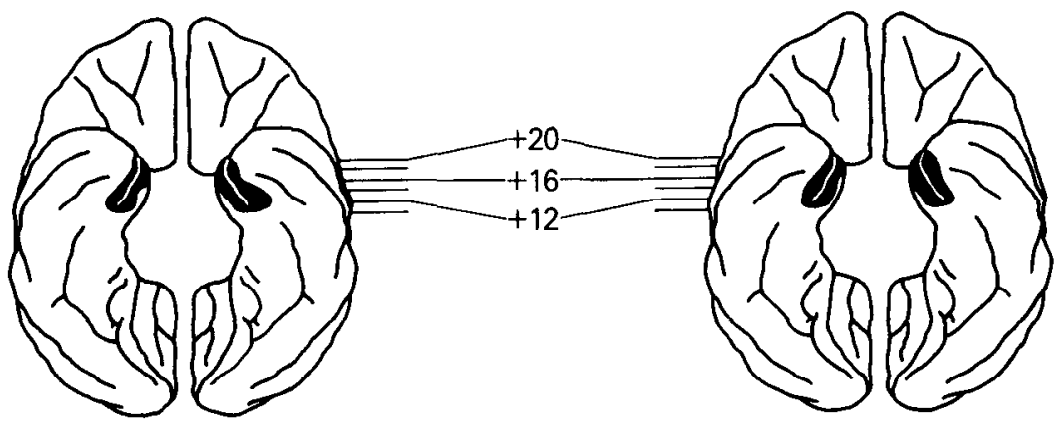

$\mathrm{A}+\mathrm{Rh}$ Case 3

Figure 7. Ablation of amygdaloid complex $(A)$ plus rhinal cortex $(R h)$, cases 2 and 3 . Note damage to the tail of the caudate nucleus unilaterally in case 2 (at levels +14 and +12 ) and bilaterally in case 3 (at levels +14 , +12 , and +10 ), indicated by oblique hatching. The anterior end of the hippocampus is visible at level +16 on the right side of the brain in case 2 (see also Fig. 8) and on the left side in case 3. Conventions as in Figure 2.

A + Rh Case 2

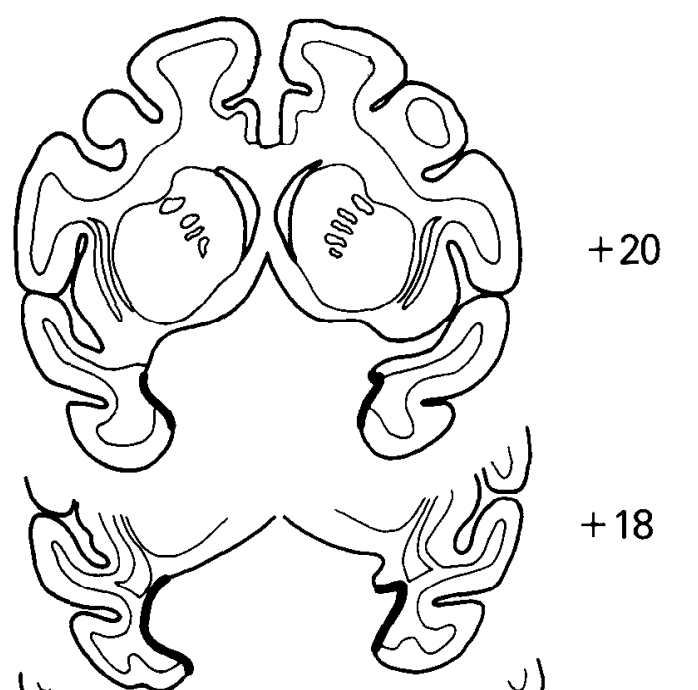

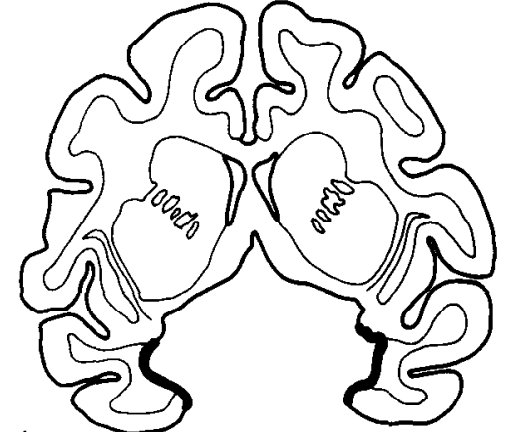
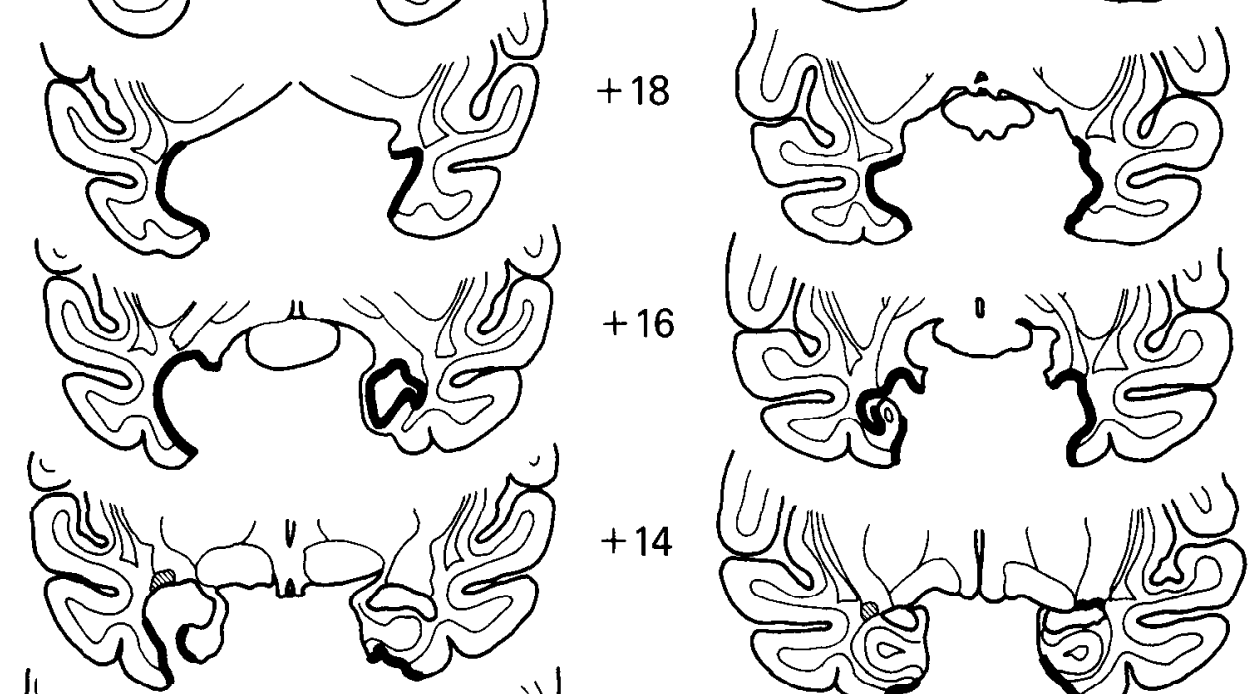

$+14$
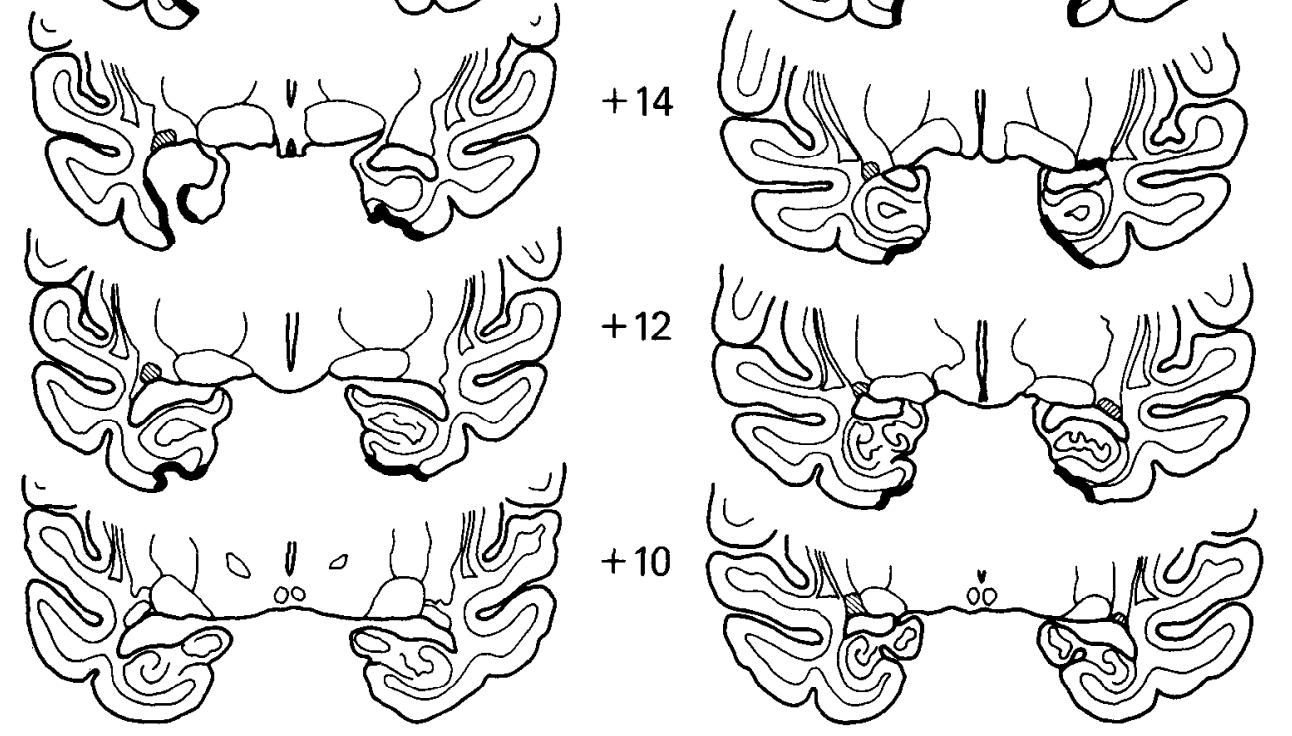

1983; see also Zola-Morgan et al., 1982). The discriminations were between two-dimensional patterns, " + " versus " $\square$ " and " $N$ " versus "W," with the first-named item of each pair serving as the positive stimulus. The discriminanda consisted of white figures on $7.5 \mathrm{~cm}^{2} \mathrm{card}-$ board plaques. The plaques, which were blue for the first discrimination and gray for the second, were presented over the lateral wells of the test tray, with the position of the positive stimulus shifted according to a predetermined, pseudorandom schedule. Monkeys were trained on the first discrimination problem for 20 trials/d until they achieved $90 \%$ correct responses on 2 consecutive $d$ or had received a maximum of 1000 trials. They were trained to the same criterion or training limit on the second discrimination problem at the rate of 30 trials/d. 

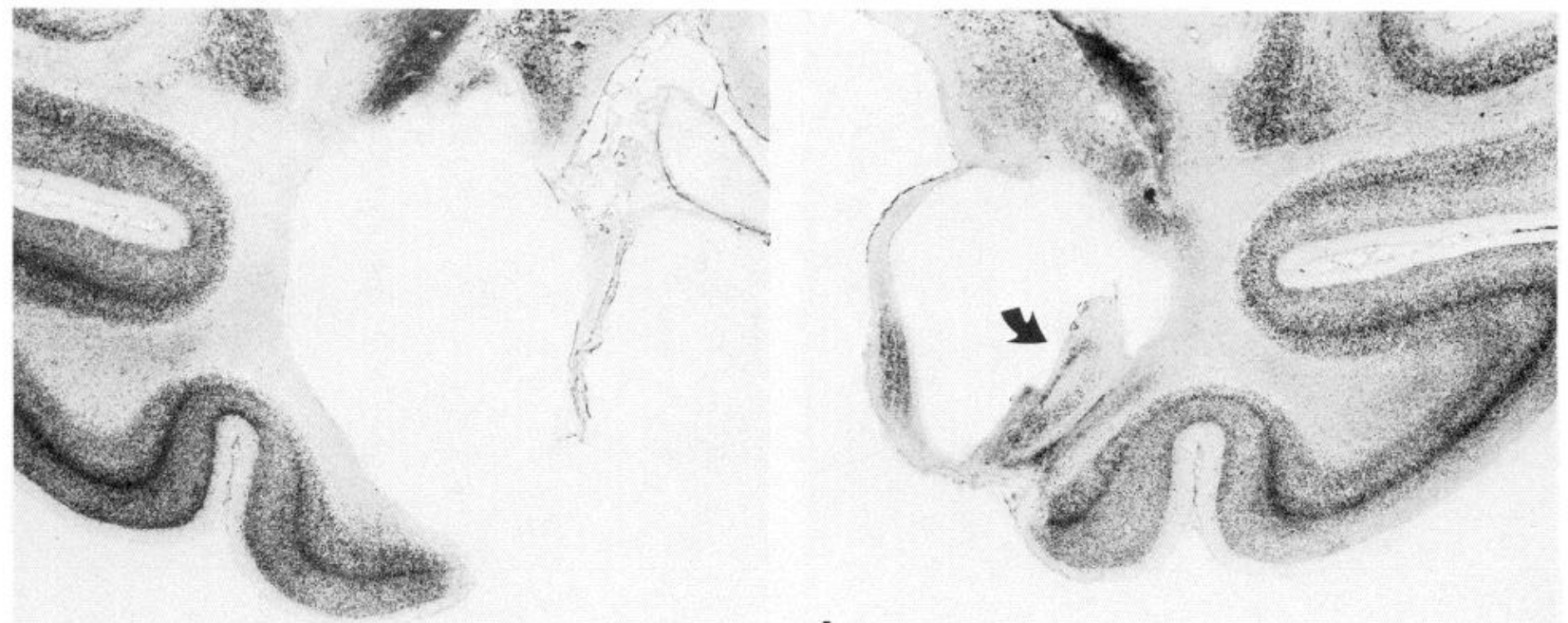

a

b
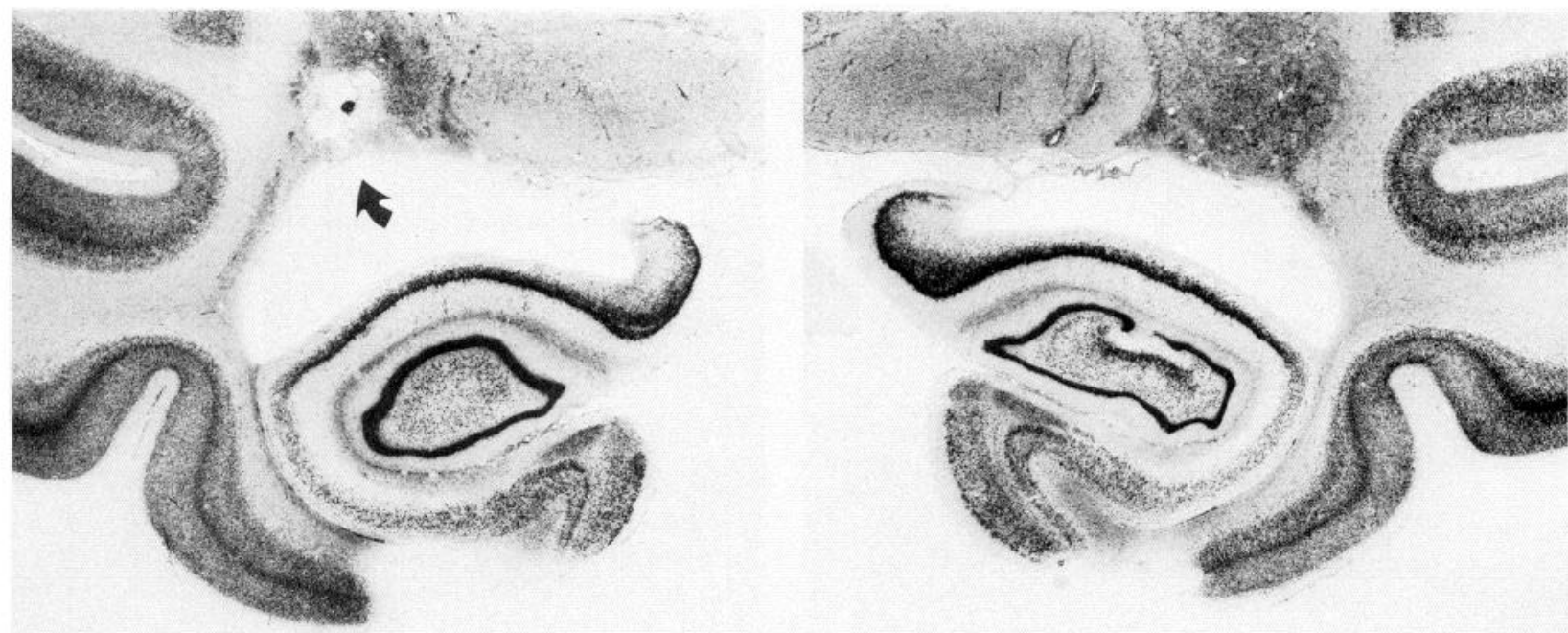

C

Figure 8. Photomicrographs of Nissl-stained coronal sections through the lesion in A + Rh case 2. Views of left side (a) and right side (b) of a single section at the level of the anterior commissure (approximately +16$)$, and of the left side $(c)$ and right side $(d)$ at the level of the anterior tip of the hippocampus (at approximately +12$)$. Note removal of the amygdaloid complex and ventromedially adjacent rhinal cortex anteriorly $(a$ and $b$ ), and of the rhinal cortex underlying the hippocampal formation posteriorly ( $c$ and $d)$. Arrow in $b$, Anterior end of hippocampus; arrow in $c$, damage to the tail of the caudate nucleus on the left. Compare with Figure 5.

\section{Spatial delayed response}

The same monkeys that were trained on the visual pattern discrimination problems were then trained on spatial delayed response, a task that required them to remember the location of a baited well for periods ranging from 0 to $10 \mathrm{sec}$. The task was administered for 30 trials daily in a manner identical to that described elsewhere (Aggleton and Mishkin, 1983). One of the lateral wells of the test tray, selected according to a pseudorandom schedule, was baited with a banana pellet while the monkey watched, after which both lateral wells were covered with identical gray cardboard plaques. There were two $0 \mathrm{sec}$ delay conditions, the first without, and the second with, the opaque screen interposed between the monkey and the test tray during the delay. (In the latter condition, the screen was lowered and then raised again as quickly as possible; this procedure served as a transition between the $0 \mathrm{sec}$ delay condition without the screen, and the longer delays with the screen.)
Criterion was set at 27 out of 30 correct responses in one session for the first condition, and at 90 correct responses in 100 trials for the second. Delays of $1-5 \mathrm{sec}$ were then imposed according to a titration schedule in which scores of 27 or more correct responses in $1 \mathrm{~d}$ were followed by testing with the next longer delay, and scores below 27 correct responses in $1 \mathrm{~d}$ were followed by testing with the next shorter delay. When the animals had attained the criterion of 27 out of 30 correct responses in $1 \mathrm{~d}$, with $5 \mathrm{sec}$ delays, they were trained to the same criterion with $10 \mathrm{sec}$ delays.

\section{Statistics}

Parametric tests (both analyses of variance with repeated measures on one factor and $t$ tests) and nonparametric tests (Mann-Whitney $U$ tests) were carried out where appropriate. Bonferroni tables, which take into account the number of animals in the group $(n)$, the number of comparisons $(k)$, and the degrees of freedom $(\nu)$, were used for comparisons between groups on delay and list-length conditions (Miller, 1980). 


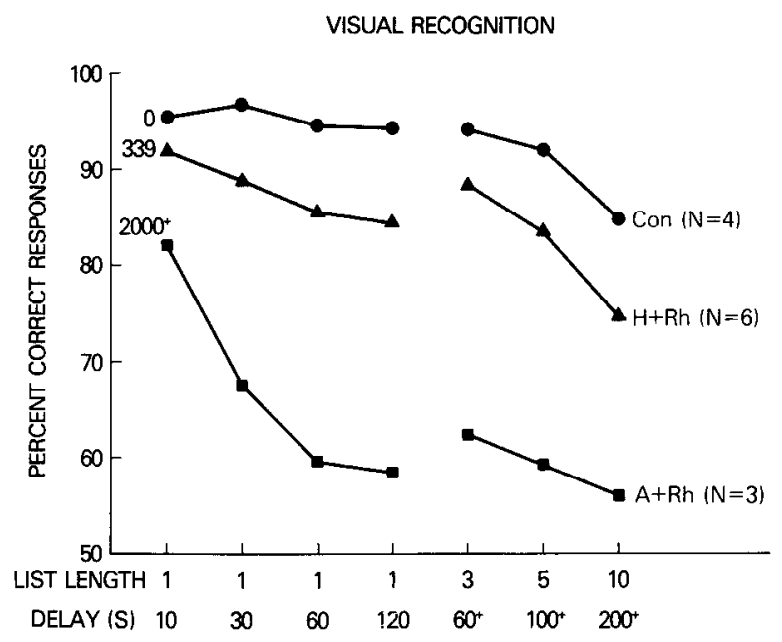

Figure 9. Delayed nonmatching-to-sample (DNMS). Numerals to the left of each curve, Average number of trials to reattain criterion on DNMS within the training limit of 2000 trials. ("+" Denotes failure to attain criterion within the training limit.) Curves on the left, Performance with increasing delays; curves on the right, with increasing list-lengths. The minimal delay between sample presentation and test for items presented in lists is indicated on the abscissa. Note extremely rapid forgetting of monkeys with the $\mathrm{A}+\mathrm{Rh}$ ablation. Con, Unoperated controls; $H+R h$, ablation of the hippocampal formation plus rhinal cortex; $A+R h$, ablation of the amygdaloid complex plus rhinal cortex.

\section{Results}

\section{General effects of surgery}

All monkeys with the $\mathrm{A}+\mathrm{Rh}$ ablations displayed the behavioral changes characteristic of amygdalectomy (Weiskrantz, 1956), including oral tendencies and hypoemotionality. Surprisingly, the monkeys with $\mathrm{H}+\mathrm{Rh}$ ablations also exhibited emotional changes relative to their preoperative state. Although none of them displayed the marked oral tendencies characteristic of monkeys with amygdaloid ablations, they did show an increased tendency to sit up front in their home cages, and were noted either to be less fearful of the investigator or to have a flatter affect than before the operation. Such changes have not been observed by us or reported by others in animals that have received hippocampectomy only.

\section{Delayed nonmatching-to-sample}

Preoperatively, the 13 monkeys learned DNMS in an average of 165 trials (range, 80-380) and 47 errors (range, 19-106).

Table 1. Spared rhinal tissue

\begin{tabular}{rlccc} 
& $\begin{array}{l}\text { Ento- and } \\
\text { prorhinal } \\
\text { cortex }^{a}\end{array}$ & $\begin{array}{l}\text { Perirhinal } \\
\text { cortex }^{a}\end{array}$ & Total & $\begin{array}{l}\text { Sparing } \\
(\%)\end{array}$ \\
\hline H + Rh 1 & 4 & 5 & 9 & 19 \\
2 & 2 & 3 & 5 & 11 \\
3 & 4 & 6 & 10 & 21 \\
4 & 9 & 12 & 21 & 45 \\
5 & 0 & 2 & 2 & 4 \\
6 & 0 & 2 & 2 & 4 \\
$\mathrm{~A}+\mathrm{Rh} 1$ & 5 & 2 & 7 & 15 \\
2 & 7 & 2 & 9 & 19 \\
3 & 0 & 0 & 0 & 0 \\
\hline
\end{tabular}

$\overline{{ }^{a} \bar{X} \mathrm{~mm}^{2} \text { per side. }}$
Table 2. Recognition memory performance test

\begin{tabular}{|c|c|c|c|c|c|c|c|}
\hline \multirow{2}{*}{ Case } & \multicolumn{3}{|c|}{ Delays (sec) } & \multicolumn{3}{|c|}{ Lists } & \multirow{2}{*}{$\begin{array}{l}\text { Aver- } \\
\text { age }\end{array}$} \\
\hline & 30 & 60 & 120 & 3 & 5 & 10 & \\
\hline \multirow[t]{4}{*}{ Con } & 99 & 93 & 94 & 94 & 93 & 89 & 93.7 \\
\hline & 96 & 98 & 97 & 93 & 86 & 78 & 91.3 \\
\hline & 98 & 92 & 99 & 96 & 96 & 89 & 95.0 \\
\hline & 93 & 95 & 87 & 93 & 93 & 83 & 90.7 \\
\hline \multirow{6}{*}{$\mathrm{H}+\mathrm{Rh}$} & 83 & 67 & 75 & 80 & 84 & 78 & 77.8 \\
\hline & 93 & 92 & 91 & 96 & 85 & 67 & 87.3 \\
\hline & 91 & 91 & 87 & 95 & 87 & 77 & 88.0 \\
\hline & 91 & 89 & 88 & 92 & 89 & 83 & 88.7 \\
\hline & 85 & 89 & 90 & 86 & 80 & 74 & 84.0 \\
\hline & 92 & 86 & 78 & 80 & 76 & 69 & 80.2 \\
\hline \multirow{3}{*}{$\mathrm{A}+\mathrm{Rh} \mathbf{1}$} & 62 & 54 & 66 & 64 & 63 & 59 & 61.3 \\
\hline & 70 & 64 & 55 & 60 & 56 & 57 & 60.3 \\
\hline & 71 & 61 & 54 & 63 & 59 & 52 & 60.0 \\
\hline
\end{tabular}

Nonparametric tests confirmed that the 3 groups that were formed $(\mathrm{A}+\mathrm{Rh}, \mathrm{H}+\mathrm{Rh}$, and Con) did not differ in their preoperative learning scores.

The results of postoperative testing on DNMS are shown in Table 2 and Figure 9. Whereas all the unoperated control monkeys displayed perfect retention, the monkeys with $\mathrm{H}+\mathrm{Rh}$ ablations required an average of 339 trials and 98 errors to reattain criterion, roughly twice the number they had required preoperatively. On the other hand, none of the monkeys with $\mathrm{A}+\mathrm{Rh}$ ablations attained criterion within the 2000 trial training limit. All group differences were significant (Mann-Whitney $U$ test; $\mathrm{H}+\mathrm{Rh}$ vs $\mathrm{A}+\mathrm{Rh}: U=0, p=0.012 ; \mathrm{H}+\mathrm{Rh}$ vs Con: $U=0, p=0.005 ; \mathrm{A}+\mathrm{Rh}$ vs Con: $U=0, p=0.028$ ).

After completing 1000 trials, the monkeys with A + Rh ablations were still scoring only about $65 \%$ correct responses. To aid them in relearning, we first gave them the benefit of shorter delays $(5-8 \mathrm{sec})$ for 500 trials, and then gave correction training as well for an additional 500 trials. The correction procedure consisted of unscored re-presentations of the choice test until the animal displaced the correct object. Following this training, the 3 monkeys were retested under standard conditions ( $10 \mathrm{sec}$ delays) for 5 additional days during which thcy attaincd final scores of 81,82 , and $83 \%$ correct responses, respectively.

On the performance test (DNMS with longer delays and listlengths), monkeys with the $\mathrm{H}+\mathrm{Rh}$ ablations were only moderately impaired, averaging about $84 \%$ correct responses across the 6 conditions, as compared with $93 \%$ for the controls. (The average score of $84 \%$ may be too low an estimate for the monkeys with $\mathrm{H}+\mathrm{Rh}$ ablations, since the performance of the poorest animal in the group, case 1, was probably due to some factor other than the surgery. This monkey obtained lower scores on some of the earlier, and easier, conditions than on later, more difficult, ones and often appeared to be unmotivated, as was evidenced by its refusal to complete numerous test sessions. Nevertheless, since there was no apparent histological basis for the anomalous behavior of this monkey, its scores were considered together with those of the other monkeys in the group.) Within the $\mathrm{H}+\mathrm{Rh}$ group, there was no correlation between the amount of spared rhinal tissue and scores on the performance test. By contrast to the monkeys with $\mathrm{H}+\mathrm{Rh}$ ablations, those with $\mathrm{A}+\mathrm{Rh}$ ablations showed extremely rapid forgetting, obtaining an average of only about $60 \%$ correct responses on the performance test. An analysis of variance with repeated measures revealed that the interaction of group and delay was significant ( $F$ with conservative degrees of freedom $(2,10)=$ $5.10, p<0.05)$, indicating that forgetting rates differed among 


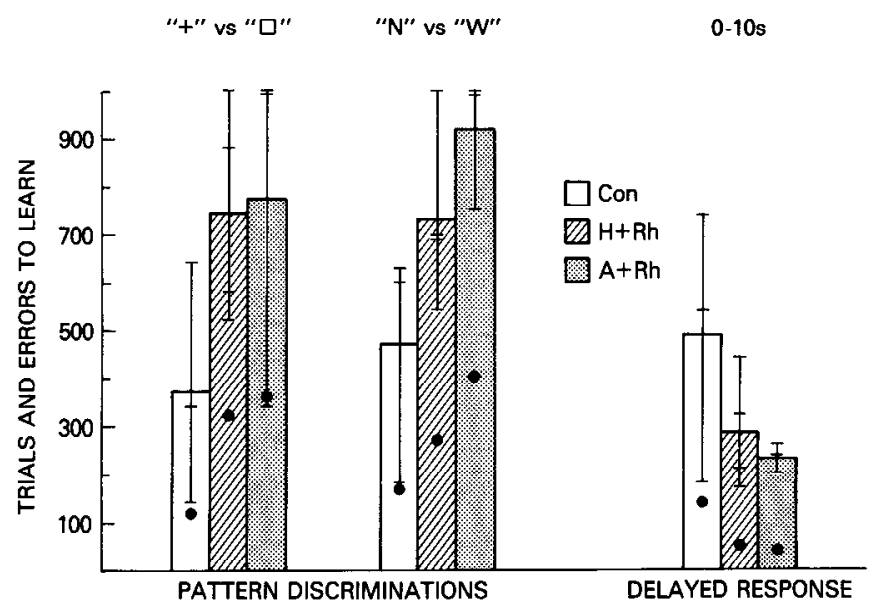

Figure 10. Pattern discriminations and spatial delayed response. Trials (bars) and errors (filled circles) in learning 2 different pattern discriminations (left side) or in learning spatial delayed response (right side) are shown for all 3 groups. Hatch marks along the small vertical bars, Scores of individual monkeys on each task. For abbreviations, see Figure 9.

the groups. Indeed, paired comparisons of the scores on the delay tests showed that all groups differed significantly $(\mathrm{H}+\mathrm{Rh}$ vs A + Rh: $t=8.20, p<0.01 ; \mathrm{H}+\mathrm{Rh}$ vs Con: $t=3.16, p<$ $0.05 ; \mathrm{A}+\mathrm{Rh}$ vs Con: $t=10.26, p<0.01$ ). No interaction of group and list-length was evident, although significant sources of variation were found in both group $[F(2,10)=55.07, p<$ $0.001]$ and list-length factors $(F$ with conservative degrees of freedom $(1,10)=26.52, p<0.001)$. All paired comparisons of list-length scores were significant $(\mathrm{H}+\mathrm{Rh}$ vs $\mathrm{A}+\mathrm{Rh}: t=8.16$, $p<0.01$; + Rh vs Con: $t=3.19, p<0.05$; A + Rh vs Con: $t=10.25, p<0.01)$.

\section{Visual pattern discriminations}

The results on the visual pattern discriminations are shown in Figure 10. Two of the differences were significant. Monkeys with $\mathrm{H}+\mathrm{Rh}$ ablations accumulated more errors (but not more trials) than the controls on the " + " versus " $\square$ " discrimination $(U=$ $1, p<0.057$ ), and monkeys with the $\mathrm{A}+\mathrm{Rh}$ ablations required more trials (but not more errors) than the controls on the " $\mathrm{N}$ " versus "W" discrimination ( $U=0, p=0.05)$. These differences were due mainly to the performance of 3 experimental monkeys that failed to learn either discrimination. One was the monkey with an $\mathrm{H}+\mathrm{Rh}$ ablation that had bilateral posterior inferior temporal damage (case 6 ), and the 2 others were those with $\mathrm{A}+$ $\mathrm{Rh}$ ablations that had bilateral damage to the tail of the caudate nucleus (cases 1 and 3). With these exceptions, which are considered further in the Discussion, the operated monkeys appeared to learn the pattern discriminations at a nearly normal rate.

\section{Spatial delayed response}

The results on spatial delayed response are also presented in Figure 10, which shows the total number of trials and errors required by each group of monkeys to attain criterion on all testing conditions. In this task, the experimental groups actually accumulated significantly fewer errors than the control group ( $\mathrm{H}+\mathrm{Rh}$ vs Con: $U=0, p=0.028 ; \mathrm{A}+\mathrm{Rh}$ vs Con: $U=0$, $p=0.05$ ), though not significantly fewer trials.

\section{Discussion}

\section{Neural substrates of recognition memory}

Complete bilateral damage to the hippocampal system, including the hippocampus proper, all the subfields of the subiculum,

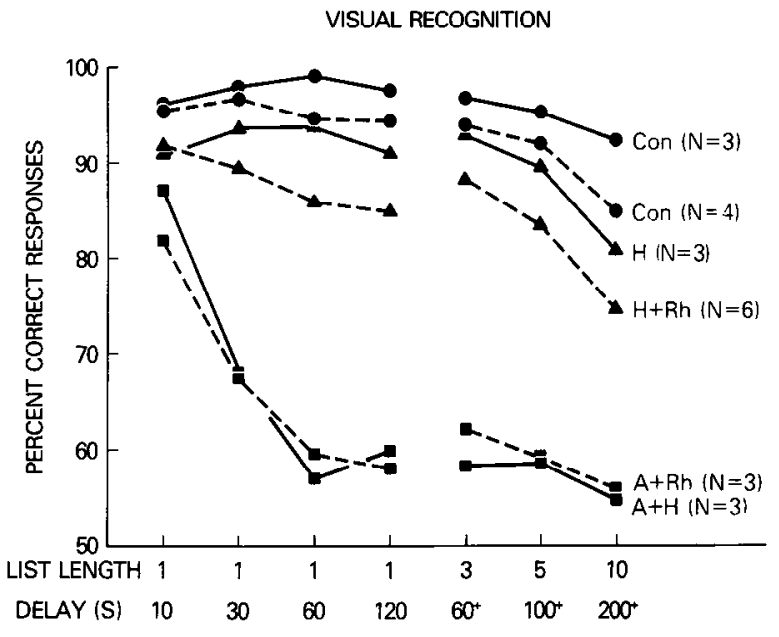

Figure 11. Comparison between the results of the present study and those for identically trained monkeys reported by Mishkin (1978). Monkeys in the earlier study (solid lines) were $M$. mulatta, whereas those in the present study (dashed lines) were $M$. fascicularis. This species difference accounts at least in part for the poorer performance of the Con and $\mathrm{H}+\mathrm{Rh}$ groups in the present study as compared with the Con and $\mathrm{H}$ groups, respectively, in the earlier study (Bachevalier and Mishkin, unpublished observations). In the earlier study, monkeys with amygdalectomy alone had scores that were indistinguishable from those of the monkeys with hippocampectomy alone. Note that addition of a rhinal cortical lesion to hippocampectomy had little or no effect, whereas addition of a rhinal cortical lesion to amygdalectomy had a marked effect. For abbreviations, see Figure 9.

the parahippocampal gyrus, and all the subdivisions of the rhinal cortex, failed to interfere substantially with recognition memory in monkeys. By contrast, amygdalectomy plus removal of only a small part of the hippocampal system, i.e., the rhinal cortex, produced a profound deficit.

The present results and those from an earlier study on the mnemonic effects of limbic lesions (Mishkin, 1978) arc compared directly in Figure 11. Since the 2 studies used different species of macaques (cynomolgus monkeys in the present study, and rhesus monkeys in the earlier one), and since an interval of several years separated the studies, any conclusions from a cross-study comparison can only be tentative. Nevertheless, it is noteworthy that the difference between the scores of the monkeys with hippocampectomy alone and of the normal controls in the earlier experiment (Mishkin, 1978) is about the same as the difference between the scores of monkeys with the $\mathrm{H}+\mathrm{Rh}$ ablations and their normal controls in the present experiment. The comparison thus suggests that the addition of the rhinal cortical removal to hippocampectomy had little additional effect. Furthermore, the level of impairment was comparable to that found following hippocampal-system lesions at many other sites (see Fig. 5 in Aggleton and Mishkin, 1985).

By contrast to the foregoing comparison, a comparison between the scores of the monkeys with amygdalectomy alone (Mishkin, 1978) and those of the monkeys with combined amygdaloid plus rhinal ablations shows that, in this case, the addition of the rhinal cortical lesion had a surprisingly severe effect. Indeed, the rhinal cortical lesion, in combination with amygdalectomy, approximated the effect of the total amygdaloid and hippocampal removal, suggesting that the rhinal cortical lesion rendered the hippocampectomy superfluous, presumably because it deafferented the hippocampal formation from its inferior temporal cortical inputs. If this interpretation is correct, the present results provide the second instance of a recognition impairment after sensory-limbic disconnection. In the first instance, such an impairment in monkeys was found following 
disconnection, by section of the anterior commissure, of all temporal lobe limbic structures in one hemisphere from inferior temporal cortical inputs arising in the other (Mishkin, 1982; Mishkin and Phillips, in press). In the present instance, the disconnection was more limited, recognition failure having been produced by disconnection of the hippocampal formation alone from its inferior temporal cortical inputs, the amygdala having been removed.

The results of the present experiment are thus consistent with the proposition, derived from earlier ablation studies, that combined damage to the amygdaloid and hippocampal systems is necessary to produce a severe recognition memory deficit. As noted in the introduction, many alternative possibilities concerning the damagc responsible for the memory failure after medial temporal ablations, including invasion of the white matter of the temporal stem, the tail of the caudate nucleus, and the inferior temporal cortex, were ruled out previously (Murray and Mishkin, 1984; Zola-Morgan et al., 1982). It is now possible to exclude, as well, damage to the "extended" hippocampal system within the medial temporal lobe-i.e., the hippocampal formation plus all the periallocortical areas within and adjacent to the rhinal sulcus.

It is important to note that, although combined damage to (or disconnection of) the amygdala and hippocampus is apparently necessary to produce a failure of recognition, the present results do not demonstrate that such damage is sufficient for the effect. As was pointed out earlier, the anatomical connections of the rhinal cortex indicate that it is a source of sensory information from all modalities, not only for the hippocampal formation (Jones and Powell, 1970; Van Hoesen and Pandya, 1975b) but also, like the amygdaloid complex, for the medial dorsal nucleus of the thalamus (Aggleton and Mishkin, 1984). Consequently, it is possible that a preserved rhinal cortex alone could sustain a significant level of recognition ability, even in the absence of both the amygdala and hippocampus. Preliminary results suggest that this is indeed the case; monkeys with combined amygdaloid and hippocampal ablations that spare the rhinal cortex appear to perform slightly better on recognition tests than monkeys in which all 3 structures have been removed or disconnected (Murray et al., 1985).

\section{Visual pattern discriminations}

Since, in a previous study (Zola-Morgan et al., 1982), removal of the amygdala, hippocampus, and rhinal cortex in combination did not yield an impairment in pattern discrimination learning, the finding in the present study of impairment on the same tasks after smaller lesions was unexpected. Presumably, the losses are to be accounted for mainly by the deviations from the intended lesions that were already described. The one monkey with the $\mathrm{H}+\mathrm{Rh}$ ablation that did not learn either pattern discrimination (case 6) had sustained the most extensive damage bilaterally to the posterior inferior temporal cortex, a region known to be critical for pattern discrimination learning (Iwai and Mishkin, 1968). Similarly, the 2 monkeys with $A+R h$ ablations that failed to learn either pattern discrimination were the 2 that had hilateral damage to the tail of the caudate nucleus, another region that is known to be important for this ability (Divac et al., 1967). The other monkey in the $A+R h$ group learned both pattern discriminations at about the normal rate, yet attained a score in recognition memory that was just as poor as the scores of the other 2 monkeys in the group. Thus, the deficit underlying the pattern discrimination impairment appears to be dissociable from that underlying the recognition impairment. This dissociation resembles that reported by ZolaMorgan et al. (1982), who found that lesions of the temporal stem disrupted visual pattern discrimination learning but not recognition memory, whereas combined ablations of the amygdala and hippocampus had the opposite effect. The available data suggest that the substrate for the acquisition of pattern discriminations includes the following temporal-lobe components: the posterior inferior temporal cortex (Cowey and Gross, 1970; Iwai and Mishkin, 1968), the whitc mattcr of the temporal stem (Horel and Misantone, 1976; Zola-Morgan et al., 1982) and temporal-lobe portions of the striatum (Buerger et al., 1974; Divac et al., 1967; and the present results). The evidence thus points to the existence of a corticostriatal pathway for pattern discrimination learning that is partially independent of the corticolimbic pathway for recognition memory (cf. Mishkin et al., 1984).

\section{Spatial delayed response}

The lack of delaycd response impairment in both experimental groups demonstrates that animals with marked recognition failure are nevertheless capable of storing some types of perceptual information, at least for short intervals (cf. Zola-Morgan and Squire, 1985). The finding that both operated groups actually made fewer errors than the normal control monkeys may perhaps be explained by an effect of the lesions on emotionality. The animals with $\mathrm{A}+\mathrm{Rh}$ ablations and, to a lesser extent, those with $\mathrm{H}+\mathrm{Rh}$ ablations as well were less fearful than the normal controls and thus perhaps more willing to observe and approach the food well as it was being baited by the investigator in full view of the monkey. Whether or not this explanation of the delayed response results is correct, it is clear that the $\mathrm{H}+\mathrm{Rh}$ lesion, like the $\mathrm{A}+\mathrm{Rh}$ lesion, resulted in a change in emotionality that is qualitatively similar to that seen following amygdalectomy alone, but that has not been reported following hippocampectomy alone. Presumably, therefore, the reduced fearfulness after the $\mathrm{H}+\mathrm{Rh}$ lesion was due to the rhinal cortical removal. This result suggests that the independent contributions of the rhinal cortex to emotional behavior, as well as to recognition memory, require further investigation.

\section{References}

Aggleton, J. P., and M. Mishkin (1983) Visual recognition impairment following medial thalamic lesions in monkeys. Neuropsychologia 21 : 189-197.

Aggleton, J. P., and M. Mishkin (1984) Projections of the amygdala to the thalamus in the cynomolgus monkey. J. Comp. Neurol. 222: $56-68$

Aggleton, J. P., and M. Mishkin (1985) Mamillary-body lesions and visual recognition in monkeys. Exp. Brain Res. 58: 190-197.

Aggleton, J. P., R. Desimone, and M. Mishkin (1986) The origin, course, and termination of the hippocampo-thalamic projections in the macaque. J. Comp. Neurol. 243: 409-421.

Bonin, G. von, and P. Bailey (1947) The Neocortex of Macaca mulatta, U. Illinois P., Urbana.

Buergher, A. A., C. G. Gross, and C. E. Rocha-Miranda (1974) Effects of ventral putamen lesions on discrimination learning by monkeys. J. Comp. Physiol. Psychol. 86: 440-446.

Cowey, A., and C. G. Gross (1970) Effects of foveal prestriate and inferotemporal lesions on visual discriminations by rhesus monkeys. Exp. Brain Res. 11: 128-144.

Divac, I., H. E. Rosvold, and M. K. S7warchart (1967) Behavioral effects of selective ablation of the caudate nucleus. J. Comp. Physiol. Psychol. 63: 184-190.

Gaffan, D. (1974) Recognition impaired and association intact in the memory of monkeys after transection of the fornix. J. Comp. Physiol. Psychol. 86: 1100-1109.

Horel, J. A., and L. J. Misantone (1976) Visual discrimination impaired by cutting temporal lobe connections. Science 193: 336-338.

Iwai, E., and M. Mishkin (1968) Two visual foci in the temporal lobe of monkeys. In Neurophysiological Basis of Learning and Behavior, N. Yoshii and N. A. Buchwald, eds., pp. 1-11, Osaka U. P., Osaka.

Jones, E. G., and T. P. S. Powell (1970) An anatomical study of converging sensory pathways within the cerebral cortex of the monkey. Brain 93: 793-820.

Miller, R. G. (1980) Simultaneous Statistical Inference, McGraw-Hill, New York.

Mishkin, M. (1978) Memory in monkeys severely impaired by com- 
bined but not separate removal of amygdala and hippocampus. Nature 273: 297-298.

Mishkin, M. (1982) A memory system in the monkey. Phil. Trans. R. Soc. Lond. [Biol.] 298: 85-95.

Mishkin, M., and J. Delacour (1975) An analysis of short-term visual memory in the monkey. J. Exp. Psychol. 1: 326-334.

Mishkin, M., and R. R. Phillips (in press) A cortico-limbic memory path revealed through its disconnection. In Brain Circuits and Functions of the Mind: Festschrift for Roger Wilcott Sperry, C. Trevarthen, ed., Cambridge U. P., New York.

Mishkin, M., B. Malamut, and J. Bachevalier (1984) Memories and habits: Two neural systems. In Neurobiology of Learning and Memory, G. Lynch, J. McGaugh, and N. Weinberger, eds., pp. 65-77, Guilford, New York.

Moss, M., H. Mahut, and S. Zola-Morgan (1981) Concurrent discrimination learning of monkeys after hippocampal, entorhinal, or fornix lesions. J. Neurosci. 1: 227-240.

Murray, E. A., and M. Mishkin (1983) A further examination of the medial temporal-lobe structures involved in recognition memory in the monkey. Soc. Neurosci. Abstr. 9: 27.

Murray, E. A., and M. Mishkin (1984) Severe tactual as well as visual memory deficits follow combined removal of the amygdala and hippocampus in monkeys. J. Neurosci. 4: 2565-2580.
Murray, E. A., J. Bachevalier, and M. Mishkin (1985) Rhinal cortex: A third temporal-lobe component of the limbic memory system. Soc. Neurosci. Abstr. 11: 461.

Saunders, R. C., E. A. Murray, and M. Mishkin (1984) Further evidence that amygdala and hippocampus contribute equally to recognition memory. Neuropsychologia 22: 785-796.

Van Hoesen, G. W., and D. N. Pandya (1975a) Some connections of the entorhinal (area 28) and perirhinal (area 35) cortices of the rhesus monkey. I. Temporal lobe afferents. Brain Res. 95: 1-24.

Van Hoesen, G. W., and D. N. Pandya (1975b) Some connections of the entorhinal (area 28) and perirhinal (area 35) cortices of the rhesus monkey. III. Efferent connections. Brain Res. 95: 39-59.

Victor, M., R. D. Adams, and G. H. Collins (1971) The WernickeKorsakoff Syndrome, Davis, Philadclphia.

Weiskrantz, L. (1956) Behavioral changes associated with ablation of the amygdaloid complex in monkeys. J. Comp. Physiol. Psychol. 49: 381-391.

Zola-Morgan, S., and L. R. Squire (1985) Medial temporal lesions in monkeys impair memory on a variety of tasks sensitive to human amnesia. Behav. Neurosci. 99: 22-34.

Zola-Morgan, S., L. R. Squire, and M. Mishkin (1982) The neuroanatomy of amnesia: Amygdala-hippocampus versus temporal stem. Science 218: 1337-1339. 